\title{
Rectified tidal transport in Lofoten-Vesterålen, northern Norway
}

\author{
Eli Børve ${ }^{1,2}$, Pål Erik Isachsen ${ }^{1,3}$, and Ole Anders Nøst ${ }^{4,5}$ \\ ${ }^{1}$ Department of Geosciences, University of Oslo, 0315 Oslo, Norway \\ ${ }^{2}$ Akvaplan-niva AS, 9296 Troms $\varnothing$, Norway \\ ${ }^{3}$ The Norwegian Meteorological Institute, 0371 Oslo, Norway \\ ${ }^{4}$ Faculty of Biosciences and Aquaculture, Nord University, 8026 Bodø, Norway \\ ${ }^{5}$ Akvaplan-niva AS, 7462 Trondheim, Norway
}

Correspondence: Eli Børve (elb@akvaplan.niva.no)

Received: 10 May 2021 - Discussion started: 26 May 2021

Revised: 4 October 2021 - Accepted: 25 October 2021 - Published: 2 December 2021

\begin{abstract}
Vestfjorden in northern Norway, a major spawning ground for the northeast Arctic cod, is sheltered from the continental shelf and open ocean by the Lofoten-Vesterålen archipelago. The archipelago, however, is well known for hosting strong and vigorous tidal currents in its many straits, currents that can produce significant time-mean tracer transport from Vestfjorden to the shelf outside. We use a purely tidally driven unstructured-grid ocean model to look into non-linear tidal dynamics and the associated tracer transport through the archipelago. Of particular interest are two processes: tidal pumping through the straits and tidal rectification around islands. The most prominent tracer transport is caused by tidal pumping through the short and strongly non-linear straits Nordlandsflaget and Moskstraumen near the southern tip of the archipelago. Here, tracers from Vestfjorden are transported tens of kilometers westward out on the outer shelf. Further north, weaker yet notable tidal pumping also takes place through the longer straits Nappstraumen and Gimsøystraumen. The other main transport route out of Vestfjorden is south of the island of Røst. Here, the transport is primarily due to tracer advection by rectified anticyclonic currents around the island. There is also an anticyclonic circulation cell around the island group Mosken-Værøy, and both cells have flow speeds up to $0.2 \mathrm{~m} \mathrm{~s}^{-1}$, magnitudes similar to the observed background currents in the region. These high-resolution simulations thus emphasize the importance of non-linear tidal dynamics for transport of floating particles, like cod eggs and larvae, in the region.
\end{abstract}

\section{Introduction}

Increased industrial activity along the Norwegian coast raises concern about potential impacts on the marine ecosystem. To properly assess risks involved, we need to understand oceanic dynamics in nearshore regions and its associated transport of nutrients and pollutants. Together with wind and freshwater runoff, strong tidal currents may dominate the flow dynamics in coastal regions on short timescales. While strong tidal currents are known to cause efficient vertical mixing of the ocean, important for bringing up nutrients in the water column (e.g., Blauw et al., 2012; Richardson et al., 2000), their contribution to net horizontal transport is often underestimated due to their oscillating nature. However, when strong tidal currents interact with complex topography in shallow waters, non-linear flow dynamics can produce significant time-mean lateral transport (Huthnance, 1973; Parker, 1991).

In this study, we will investigate non-linear tidal dynamics around Lofoten-Vesterålen in northern Norway (Fig. 1), a major spawning ground for the northeast Arctic cod (Hjermann et al., 2007). Spawning of this species takes place all along the middle and northern Norwegian coast, but as much as $40 \%$ of the cod spawn in Vestfjorden southeast of the Lofoten-Vesterålen archipelago (Ellertsen et al., 1981; Sundby and Bratland, 1987). Therefore a good understanding of ocean dynamics controlling the drift and spreading patterns of biogeochemical material in this region, and cod eggs and larvae in particular, is important for identifying factors controlling the recruitment of the northeast Arctic cod. 
The majority of studies on transport in the Lofoten and Vesterålen region have focused on the large-scale ocean dynamics (e.g., Ådlandsvik and Sundby, 1994; Vikebø et al., 2007; Opdal et al., 2008). For example, the transport of cod eggs and larvae out of Vestfjorden itself has been reported to mainly take place around the southern tip of the LofotenVesterålen archipelago (Vikebø et al., 2007; Opdal et al., 2008), following the larger-scale background currents, notably the Norwegian coastal current, and currents that respond to sporadic wind events. Even though tides are strong in the region (Moe et al., 2002; Gjevik et al., 1997), the contribution of tidally driven transport has gained little attention.

A large number of straits cut through the LofotenVesterålen archipelago, and these straits are well known for hosting strong and vigorous tidal currents. This includes a set of narrow and relatively long straits along the northern half of the archipelago, but even more so two to three wider but shorter straits over the shallow ridge southwest of Lofotodden (Moe et al., 2002). Here, near the southern tip of Lofoten, Moskstraumen is situated, also called the Lofoten maelstrom and famous for its vigorous and deadly currents. For the interested reader, tales, stories and observations of the Lofoten maelstrom can be traced all the way back to the medieval ages (see Gjevik et al., 1997). It seems clear that the vigorous tidal transport and dispersion around Moskstraumen in particular, but also in other straits of Lofoten, can impact the net exchanges between Vestfjorden and the shelf outside. Existing studies have focused on quantifying tidal dispersion rates (Lynge et al., 2010) and on establishing a link between tidal dispersion and transport by time-mean currents (Ommundsen, 2002). There has, however, been less attention put on identifying and quantifying the underlying non-linear dynamics responsible for tidal dispersion and transport. Two such non-linear processes that are likely to be important in our region, and will therefore be the focus of the present study, are tidal pumping and tidal rectification.

Tidal pumping in a strait is a Reynolds flux of properties caused by a temporal asymmetry in circulation patterns between the flood and ebb phases of the tide (Geyer et al., 2001). The process can be explained using the simple model of Stommel and Farmer (1952), as sketched in Fig. 2. When tidal currents enter a strait, say from the open-ocean side, we expect them to behave roughly as potential flow and be steered by the coastline into the opening. So water from a wide region around the opening, the "sink region", is pulled into the strait (Fig. 2a). In contrast, when the flow exits the strait during the subsequent phase of the tide, the joint effect of friction and an adverse non-linear pressure gradient as the strait opens up might cause the flow to separate from the coastline (Kundu et al., 2016). If there is such flow separation, the exiting water will continue straight ahead as a tidal jet (Fig. 2b). The areas covered by the sink region and the tidal jet are equally large, but they take on different shapes. Some regions are overlapping while others are not. The existence of non-overlapping regions will cause some difference

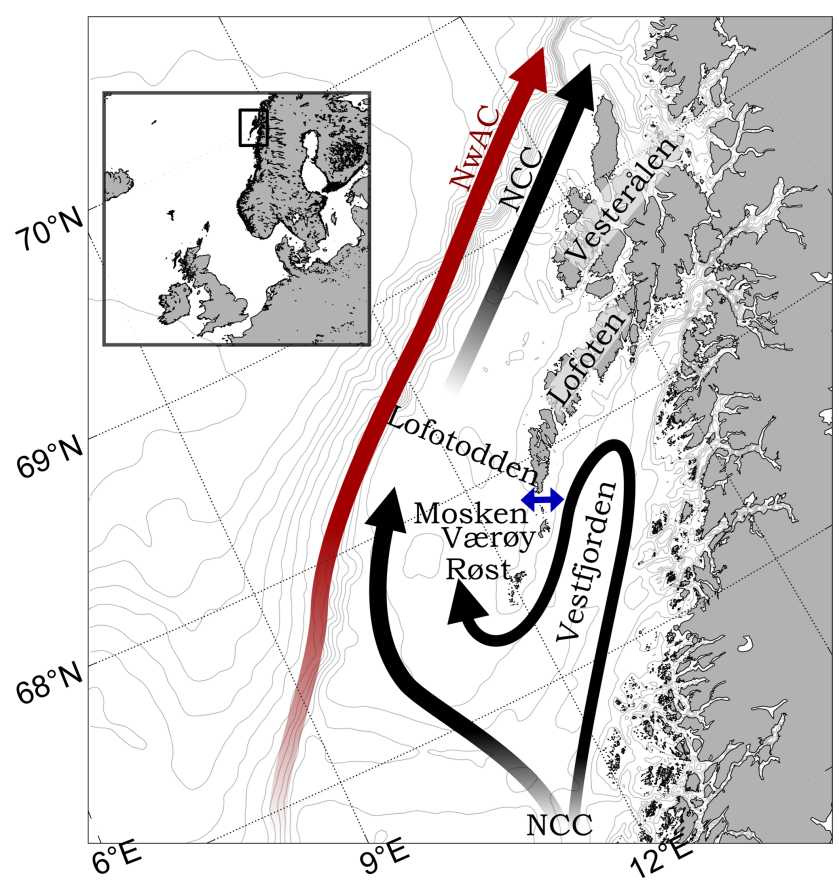

Figure 1. The general ocean surface circulation in the LofotenVesterålen region. Black arrows show the Norwegian Coastal Current $(\mathrm{NCC})$ and the red arrow shows the Norwegian Atlantic Current (NwAC). The blue two-headed arrow shows the location of Moskstraumen, situated between Lofotodden to the north and the small island of Mosken to the south.

in which waters flow into and out of the strait (Fig. 2). More recent studies have found that the presence of a tidal jet on the outflow from a strait is intimately related to the formation of self-propagating dipoles at the strait exit (Wells and van Heijst, 2003; Afanasyev, 2006; Nøst and Børve, 2021). The dipoles emerge from vortices that form at the points where the flow separates from the coastline, one at each side of the strait exit. The vortices become a self-propagating dipole when the strait is narrow enough for the two to interact, so that the velocity field of one vortex begins to advect the vorticity of the other. This self-propagating dipole is then trailed by the tidal jet. As it turns out, most of the water that exits the strait is injected into the dipole and its trailing jet (Nøst and Børve, 2021). Therefore, if the dipole avoids being drawn back into the strait during the subsequent potential flow phase of the tide, the result will be a net property exchange through the strait (Kashiwai, 1984; Wells and van Heijst, 2003; Nøst and Børve, 2021).

The second process, rectification of oscillating currents around isolated islands and banks, has been observed in several regions where cross-slope tidal currents are prominent. The phenomenon can be explained as a response to a nonlinear momentum transport convergence by the oscillating currents (Huthnance, 1973; Loder, 1980) or, alternatively, a net cross-slope vorticity flux by the same oscillations (Zimmerman, 1978; Robinson, 1981). The generation of a net 


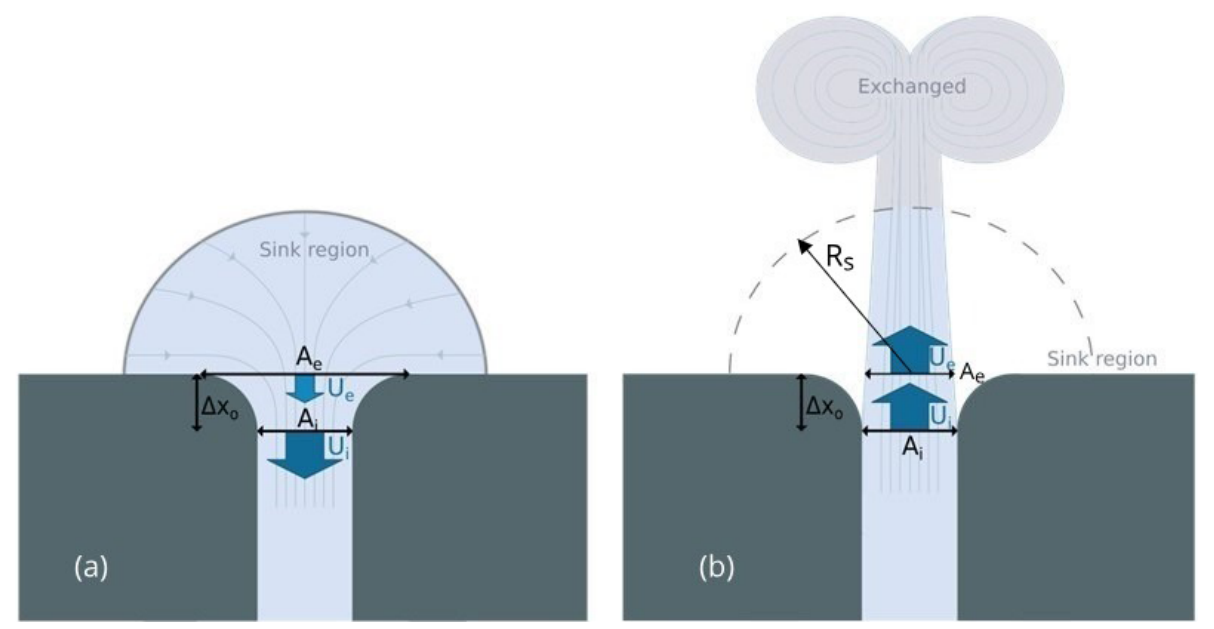

Figure 2. A sketch illustrating the flow asymmetry that leads to tidal pumping. The left panel (a) shows the tidal current entering the strait from all directions during ebb tide. The right panel (b) shows the tidal current exiting the same strait during flood tide; the flow now separates from the coastline and a dipole with a trailing jet forms and propagates away from the strait. $U$ is the tidal current speed and $A$ is the cross-sectional area. Subscripts " $i$ " and "e" correspond to the inner and outer sides of the strait opening, respectively. $\Delta x_{\mathrm{O}}$ is the length of the strait opening where we evaluate the flow asymmetry and the non-linearity of the flow dynamics. $R_{\mathrm{S}}$ measures the effective size of the "sink region" from which waters enter the strait during ebb.

vorticity flux can be understood by imagining following a water column that moves periodically up and down the topographic slope of a bank, driven by a large-scale tidal potential, as sketched in Fig. 3 (Zimmerman, 1978, 1981). In the Northern Hemisphere, the column attains negative vorticity on its way up the slope and positive vorticity on its way down due to vortex squeezing and stretching, respectively. Bottom friction then removes some negative vorticity from the column over shallow regions and some positive vorticity over deep regions. A sustained oscillation, driven by the largescale tidal potential, will hence be associated with a positive vorticity flux from shallow to deep regions. In a quasi-steady state, the vorticity flux from many such columns may be balanced by bottom friction acting on a time-mean anticyclonic circulation around the bank. Additionally, a net vorticity flux across a sloping bottom can be generated by differential bottom friction acting on water columns that are made to oscillate along the sloping bottom (Zimmerman, 1978; Loder, 1980; Pingree and Maddock, 1985; Maas et al., 1987). In this case, the direction of the vorticity flux will depend on the orientation of the tidal ellipses relative to topography, but the end result will also be time-mean currents around islands and banks.

Indication of large dipole vortices associated with tidal currents have been observed in satellite images from Moskstraumen (see, e.g., Fig. 4), indicating that at least tidal pumping may be of importance in the Lofoten-Vesterålen region. The rectification of tidal currents has not, to our knowledge, been observed or studied before in this region. But strong tidal oscillations around the island groups MoskenVærøy and Røst off the southern tip of the archipelago sug- gest that this is a process worth investigating. In the presence of interactions with smaller-scale non-conservative flow dynamics, such time-mean circulation cells may very well act as "gears" that transport cod eggs and larvae, as well as nutrients and pollutants, between Vestfjorden and the outer shelf.

In this paper, we will isolate these two potential transport mechanisms by conducting and analyzing a purely tidally forced numerical simulation of the region. Modeling nonlinear tidal dynamics in such a complex region is challenging. Lynge et al. (2010) found that modeled tidally driven transport through Moskstraumen is highly dependent on the model grid resolution and that a horizontal resolution down to $50-100 \mathrm{~m}$ is required to resolve key non-linear dynamics and thus obtain realistic transport estimates. This resolution in much higher than what is typically used in, e.g., operational transport models of the region. Our approach to this practical problem is to use an unstructured-grid model which allows very high resolution in straits where non-linear tidal dynamics is thought to be important. At the same time the flexible mesh allows us to reduce resolution away from complex geometry, thus enabling us to run simulations over a large enough domain to provide a good representation of the northward-propagating tidal waves. The model setup and a validation against available observations are summarized in Sect. 2. The two dynamical processes are then discussed separately in Sect. 3. Finally, a brief summary of results in Sect. 4 wraps up the study. 


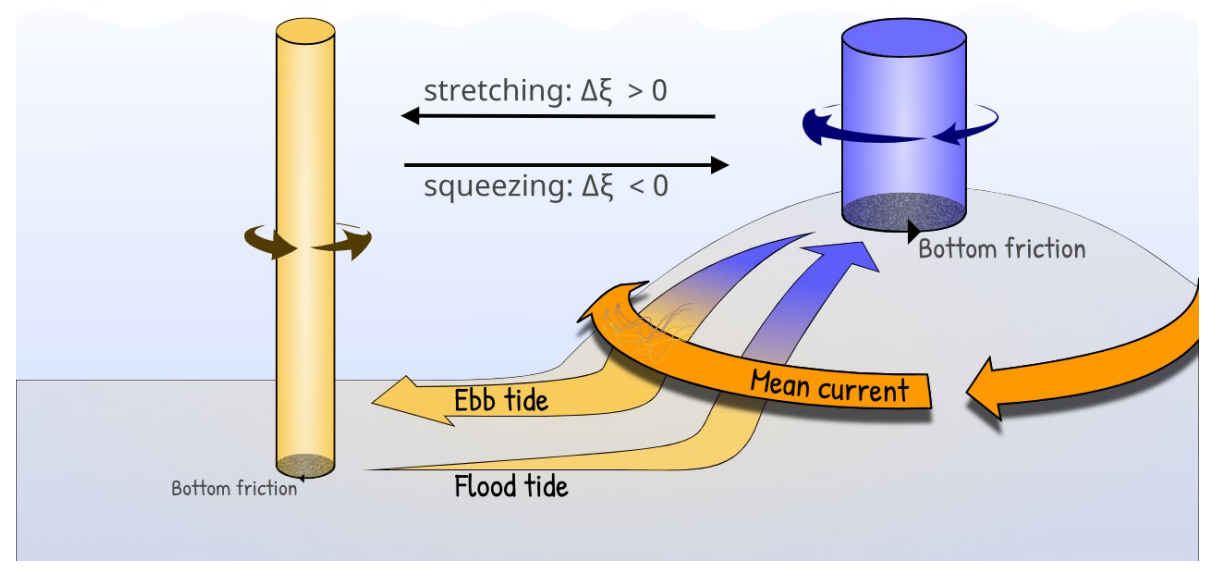

Figure 3. A sketch of mean-flow generation around a bank from oscillating flow across the bank topography. A water column oscillates up and down topography, attaining negative vorticity $\xi$ on its way up the slope and positive vorticity on its way down due to vortex squeezing and stretching, respectively. Bottom friction removes some negative vorticity from the column over shallow regions and some positive vorticity over deep regions. A sustained oscillation, by a large-scale tidal potential, will be associated with a positive vorticity flux from shallow to deep water. The vorticity flux from many such columns is balanced by a mean anticyclonic circulation around the bank.
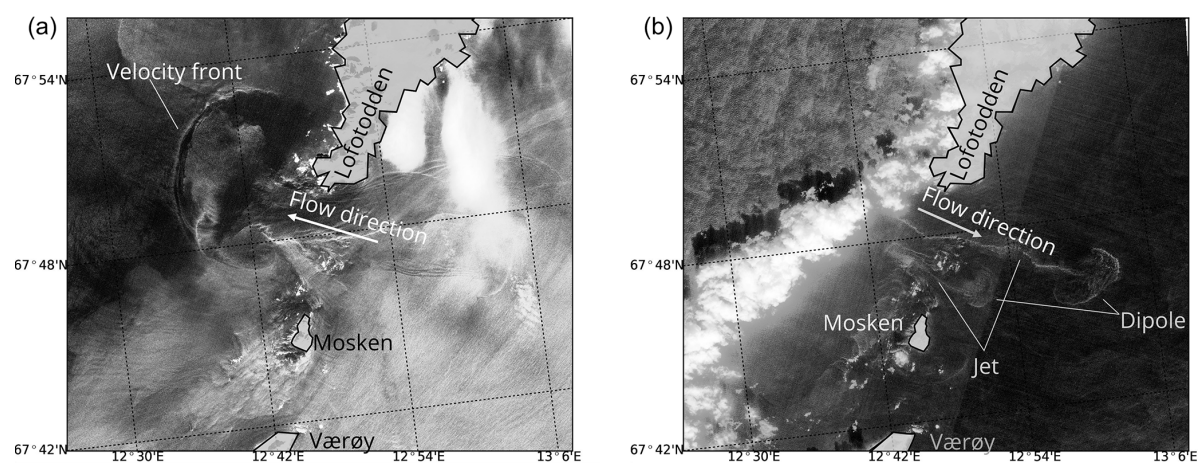

Figure 4. Satellite images from Copernicus Sentinel-2 missions, tracing out surface currents in Moskstraumen and Nordlandsflaget. Panel (a) shows the current structure during westward flow (flood tide); west of Lofotodden, a velocity front is evident which is likely related to dipole formation. Panel (b) shows the current structure during eastward flow (ebb tide); here, a dipole east of the strait with a trailing jet is evident. The Sentinel-2 missions satellites carry a multi-spectral instrument with 13 spectral channels in the shortwave infrared and visible-near-infrared spectral range, whereas this image is collected from band B4 (664.6 nm). The satellite imagery was assessed and processes using data from the Norwegian National Ground Segment for Sentinel data (Halsne et al., 2019, Trygve Halsne, personal communication, 2021).

\section{Model description}

We use the Finite Volume Community Ocean Model (FVCOM; Chen et al., 2003) for modeling tidal flows in the Lofoten-Vesterålen region. FVCOM is a prognostic, freesurface, three-dimensional primitive equation ocean model which solves the integral form of the equations on an unstructured triangular horizontal grid and a terrain-following vertical grid. For this study of lateral transport dynamics, we used a two-dimensional version of FVCOM, leaving out buoyancy effects. The model calculates momentum advection using a second-order accuracy flux scheme (Chen et al., 2013; Kobayashi et al., 1999), horizontal diffusion of momentum by the Smagorinsky closure scheme (Smagorinsky, 1963) and quadratic bottom friction using a depth-dependent drag coefficient. The governing equations are integrated in time using a modified explicit fourth-order Runge-Kutta timestepping scheme (Chen et al., 2013).

The model domain, with coastline and bottom depths, is shown in Fig. 5. The unstructured triangular grid enables us both to resolve small-scale non-linear flow dynamics near land as well as the large-scale behavior of the tidal waves. Along the coast the grid resolution is as high as $30-50 \mathrm{~m}$, which provides us with a minimum of five grid cells across the narrowest cross-sections inside straits and inlets. Most straits are, however, resolved with more that five grid cells, as illustrated by Nappstraumen in the right panel of Fig. 5. Such high resolution near land allows us to model flow separation and the development of eddies, which are important pro- 


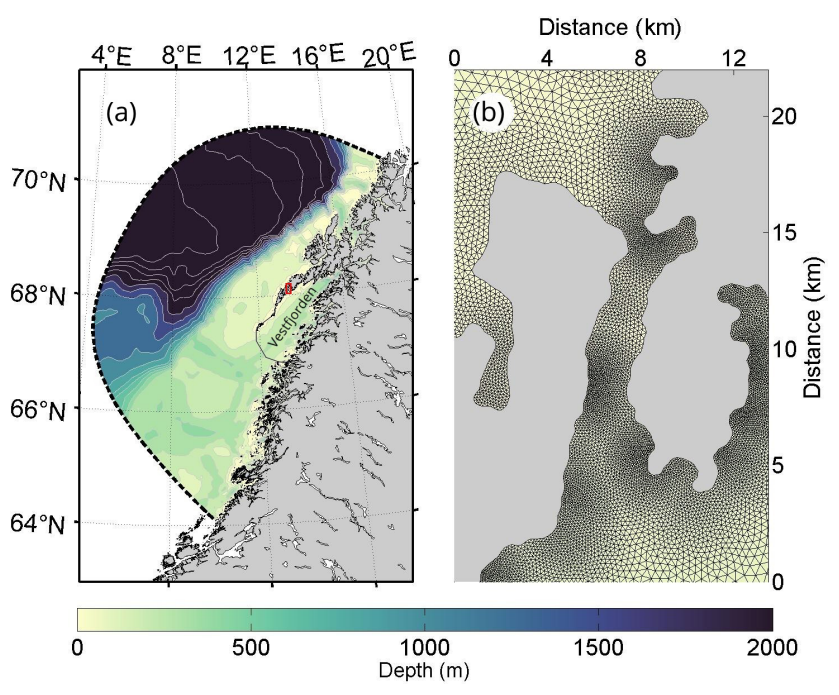

Figure 5. The model domain for the unstructured-grid modeling. Panel (a) shows the bathymetry inside the model domain. The thick dotted black line shows the outer open boundary of the model. The thin black line bordering Vestfjorden outlines the boundary of the region where we release a tracer. Panel (b) shows an example of the varying triangular grid resolution near Nappstraumen, highlighted by the red rectangle in panel (a).

cesses for generating non-linear tidal transport. The grid resolution decreases monotonically away from land and steep topography, down to around $5 \mathrm{~km}$ along the open boundary away from the coastline.

Along the open boundary, we force the model with prescribed sea surface height (SSH) anomalies due to northward-propagating tidal waves. We obtain the SSH forcing fields from the TPXO 7.2 assimilated tidal model (Egbert and Erofeeva, 2002) from which we include all major constituents. The surface elevation is specified at the boundary nodes. Velocities in FVCOM are calculated in the center of each triangular cell and not directly at the boundary. The velocities in the open boundary cells are calculated based on the assumption of mass conservation (Chen et al., 2003, 2011).

We spin the dynamics of FVCOM up for 6 months before analyzing the model fields. In order to investigate tidal transport dynamics, we couple FVCOM with a passive tracer module, the Framework for Aquatic Biogeochemical Models (FABM; Bruggeman and Bolding, 2014). After the 6-month spin-up period, we release a passive tracer of concentration $1 \mathrm{~m}^{-3}$ inside Vestfjorden (bounded by the thin black lines shown in the left panel of Fig. 5). The tracer concentration is set to zero outside. The tracer is released around slack tide after ebb tide (from just before slack tide to approximately half an hour into flood tide depending of the geographic location inside Vestfjorden). After this initial tracer release, we run the coupled model for another 2 months to ensure that we capture effects of the spring-neap cycle.

\section{Model validation}

The large-scale behavior of the M2 and K1 tidal waves and associated currents is shown in Fig. 6. The semi-diurnal M2 wave (left panels) is the dominating constituent in the region. The wave is scattered and deflected around the Lofoten archipelago. The fraction of the wave that enters Vestfjorden slows down and the SSH amplitude increases towards the head of the fjord due to the geometry of the fjord. In contrast, the fraction of the wave that passes west of the archipelago speeds up along the narrowing shelf. The result is a small phase shift and a large difference in SSH amplitude between Vestfjorden and the outer side of the archipelago. This generates strong tidal currents in the straits (lower left panel). Particularly strong currents are found over the narrow and shallow ridge south of Lofotodden.

The K1 wave is the dominating diurnal constituent (right panels), but its amplitude in SSH is only about $1 / 10$ of the M2 amplitude. The K1 wave behaves similarly to the M2 wave inside Vestfjorden, and a gradient in SSH across the archipelago produces strong diurnal tidal currents as well through the straits (lower right panel). Interestingly, along the narrow outer shelf vest of the archipelago, we observe that the K1 tidal current amplitude increases northward, particularly west of Vesterålen. For comparison, the M2 tidal current amplitude decreases in the same area. This prominent amplification of the diurnal tidal component, $\mathrm{K} 1$, has been attributed to the generation of diurnal continental shelf waves by Ommundsen and Gjevik (2000) and Moe et al. (2002).

The large-scale behavior of both M2 and K1 waves in our model corresponds well with results reported earlier by Gjevik et al. (1997) and Moe et al. (2002). Furthermore, the sea surface height and phase from the model fit reasonably well with observations from five stations provided by the Norwegian Mapping Authority, Hydrographic Service (2021), as shown in Fig. 7. One notable exception is the phase of the S2 tide, but the amplitude of this is very small compared to the other constituents. The modeled tidal current amplitudes also agree well with observations (also shown in Fig. 7c). Here, we also observe that the $\mathrm{K} 1$ tidal current dominates in station 8 , Sortlandssundet, which corresponds to the enhanced current velocities for the diurnal K1 tide in Vesterålen seen in the lower right panel of Fig. 6. Corresponding values for $\mathrm{M} 2$ and $\mathrm{K} 1$ are given in Tables 1 and 2. In general, we find that the overall performance of our FVCOM tidal simulation is acceptable, providing a good foundation for investigating tidal transport dynamics in the region.

\section{Tidally driven tracer transport in Lofoten}

Figure 8 shows a $3 \mathrm{~d}$ average of the tracer concentration near the end of the simulation period. We observe a pronounced net tracer exchange between Vestfjorden and the shelf outside, particularly south of Lofotodden. Water with 
Table 1. Amplitude and phase of modeled and observed sea surface height for M2 and K1 tidal constituents. The difference is given as model minus observation. Observations are collected from the Norwegian Mapping Authority, Hydrographic Service (2021) (also displayed in Fig. 7).

\begin{tabular}{|c|c|c|c|c|c|c|c|c|c|c|}
\hline \multirow[b]{2}{*}{ Station } & \multicolumn{4}{|c|}{ Model } & \multicolumn{4}{|c|}{ Observed } & \multicolumn{2}{|c|}{ Difference } \\
\hline & $A_{\eta}(\mathrm{m})$ & $(95 \% \mathrm{CI})$ & $g_{\eta}\left({ }^{\circ}\right)$ & $(95 \% \mathrm{CI})$ & $A_{\eta}$ & $(95 \% \mathrm{CI})$ & $g_{\eta}$ & $(95 \% \mathrm{CI})$ & $A_{\eta}(\mathrm{m})$ & $g_{\eta}\left({ }^{\circ}\right)$ \\
\hline \multicolumn{11}{|l|}{ M2 } \\
\hline Bodø (B) & 0.854 & $(0.006)$ & 332 & $(0.4)$ & 0.878 & $(0.008)$ & 331 & $(0.5)$ & -0.024 & 1 \\
\hline Kabelvåg (K) & 0.903 & $(0.006)$ & 335 & (0.4) & 0.937 & (0.007) & 336 & $(0.4)$ & -0.034 & -1 \\
\hline Harstad (H) & 0.677 & $(0.005)$ & 348 & $(0.5)$ & 0.708 & $(0.005)$ & 343 & $(0.4)$ & -0.031 & 5 \\
\hline Narvik (N) & 0.973 & $(0.006)$ & 335 & $(0.3)$ & 1.01 & $(0.008)$ & 335 & $(0.462)$ & -0.037 & 0 \\
\hline Andenes (A) & 0.631 & $(0.004)$ & 347 & $(0.4)$ & 0.668 & $(0.005)$ & 342 & $(0.5)$ & -0.037 & 5 \\
\hline \multicolumn{11}{|l|}{ K1 } \\
\hline $\operatorname{Bod} \varnothing(\mathrm{B})$ & 0.0988 & $(0.002)$ & 209 & (1.1) & 0.110 & $(0.003)$ & 204 & (1.9) & -0.011 & 5 \\
\hline Kabelvåg (K) & 0.100 & $(0.002)$ & 212 & (1.1) & 0.111 & $(0.004)$ & 207 & $(2.2)$ & -0.011 & 5 \\
\hline Harstad (H) & 0.0595 & $(0.002)$ & 198 & (1.5) & 0.062 & $(0.003)$ & 209 & (3.0) & -0.003 & -11 \\
\hline $\operatorname{Narvik}(\mathrm{N})$ & 0.102 & $(0.002)$ & 211 & (1.1) & 0.116 & $(0.003)$ & 207 & (1.8) & -0.014 & 4 \\
\hline Andenes (A) & 0.068 & $(0.002)$ & 175 & (1.6) & 0.0706 & $(0.002)$ & 200 & (2.0) & -0.003 & 25 \\
\hline
\end{tabular}

Table 2. Amplitude of modeled and observed tidal velocity for M2 and $\mathrm{K} 1$ tidal constituents. The difference is given as model minus observation $(M-O)$. Observations are collected from Table 3 of Moe et al. (2002) (also displayed in Fig. 7).

\begin{tabular}{lrrr}
\hline & Model & Observed & Difference \\
\cline { 2 - 4 } Station & $A_{u}\left(\mathrm{~m} \mathrm{~s}^{-1}\right)$ & $A_{u}\left(\mathrm{~m} \mathrm{~s}^{-1}\right)$ & $A_{u}\left(\mathrm{~m} \mathrm{~s}^{-1}\right)$ \\
\hline M2 & & & \\
\hline St1 & 0.078 & 0.096 & -0.018 \\
St2 & 0.201 & 0.212 & -0.012 \\
St3 & 0.149 & 0.116 & 0.033 \\
St4 & 0.085 & 0.073 & 0.012 \\
St5 & 0.126 & 0.098 & 0.023 \\
St6 & 0.019 & 0.269 & -0.250 \\
St7 & 0.022 & 0.017 & 0.005 \\
St8 & 0.201 & 0.130 & 0.071 \\
St9 & 0.056 & 0.035 & 0.021 \\
St10 & 0.113 & 0.833 & -0.720 \\
St11 & 1.758 & 1.139 & 0.619 \\
& & & \\
\hline K1 & & & \\
\hline St8 & 0.562 & 0.485 & 0.077 \\
\hline
\end{tabular}

tracer concentration exceeding $0.3 \mathrm{~m}^{-3}$ is transported tens of kilometers westward on the outer shelf from this southernmost region. We also observe notable tracer transport through the longer straits Nappstraumen (4) and Gimsøystraumen (5) somewhat further north. In contrast, only a very small amount of tracer appears to be transported through the long and narrow Raftsundet (6) and Tjeldsundet (7) even further to the northeast.
A visual comparison with Fig. 6 suggests that the transport scales roughly with the intensity of tidal currents, but here we will have a closer look at the actual dynamics at play. As outlined above, the focus will be on two processes. The first is essentially a Reynolds "pumping" of a passive tracer through straits, stemming from a correlation between fluctuations in the tidal velocity and fluctuations in tracer concentration. The the second is the generation of rectified currents around islands. We set out to clarify and summarize key theoretical aspects of each process as well as check their applicability in Lofoten-Vesterålen.

\subsection{Tidal pumping}

Tidal pumping through a strait is a property exchange associated with zero net mass transport (i.e., a Reynolds flux) caused by a temporal asymmetric flow field between the ebb and the flood tide (Stommel and Farmer, 1952). The flow asymmetry arises where inflow to a strait takes the form of a broad potential flow whereas outflow is concentrated in a jet generated after flow separation. When the tidal current exits a strait, the flow decelerates as the cross-sectional area increases. If the deceleration is rapid enough for non-linear dynamics to dominate, there will be a dynamic low pressure in the strait and high pressure outside the opening. In that case, both the pressure gradient and bottom friction act against the flow direction, and currents near the coast where friction is strongest might be brought to halt and even reverse, resulting in flow separation (Kundu et al., 2016; Signell and Geyer, 1991). Flow separation and corresponding flow asymmetry are typically present in straits that have strong tidal currents and abrupt openings. As also pointed out in the introduction, the generation of a tidal jet on outflow through an 

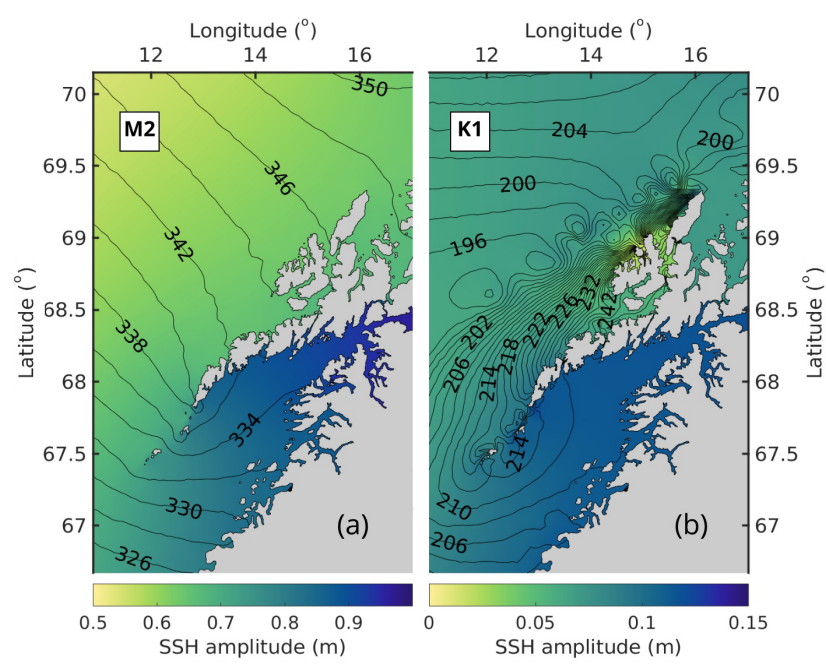

grow in time, as can be seen at 3 and $4.5 \mathrm{~h}$. The vortices clearly capture and transport waters with high tracer concentration northward as they propagate away from the strait during flood tide, as expected from theory.

The ebb tide (7.5, 9 and $10.5 \mathrm{~h}$ in Fig. 9) returns water to the northern opening as potential flow, following the shape of the coastline. The flow paths are thus distinctly different compared to those during flood tide, and waters with low tracer concentration are drawn back in, particularly along the western flanks of the strait. In this particular strait, the selfpropagating dipole, formed during flood, is strong enough to escape the return flow. The bulk of the tracer captured by the two vortices therefore remains at the northern side, contributing significantly to the net tracer transport through Nappstraumen over the course of the full tidal cycle. At the more gradual southern opening of the strait, there is much less indication of flow separation. There is suggestion of a small and weak vortex pair forming along the southwestern flank, but the net tracer transport appears to be limited.

The situation is somewhat different in Moskstraumen (3) between Lofotodden and the island of Mosken, as show in Fig. 10. Here, there is flow separation, dipole and jet formation at both exits during flood and ebb tide, respectively. A closer inspection shows that the dipoles form later in the tidal cycle compared to the generation at the northern exit in Nappstraumen ( $3 \mathrm{~h}$ compared to $1.5 \mathrm{~h}$ ), and their propagation distance is somewhat shorter when the flow reverses. Even so, their propagation speed is strong enough that the bulk of the dipoles avoid being transported back into the strait by the return flow. The inflow to Moskstraumen, in contrast, also primarily takes the form of potential flow, drawing fluid into the strait from all directions. The result is a large net tracer transport which is clearly seen in Fig. 8. A dipole with a trailing jet is also observed to form during ebb tide (10.5 h) in Nordlandsflaget (2) a few kilometers to the southwest between the islands Mosken and Værøy. This flow feature brings low-concentration waters into Vestfjorden, but the net effect appears to be somewhat dwarfed by the pumping that takes place in Moskstraumen.

abrupt strait opening is intimately tied to the presence of a self-propagating dipole.

Before making quantitative estimates, we take a look at the flow field in two of the straits. Figure 9 shows the flow and tracer field in Nappstraumen (4) through one tidal cycle. The various panels show the situation at various times after slack tide after ebb tide. So, the first three panels (1.5, 3 and $4.5 \mathrm{~h}$ ) show conditions during the flood tide while the last three (7.5, 9 and $10.5 \mathrm{~h}$ ) show conditions through the following ebb. Already at $1.5 \mathrm{~h}$ after slack tide, we see that the northward-flowing tidal current has separated from the coast near the abrupt opening in the north. The separation has created two oppositely signed vortices that are trailed by a jet, in line with previous studies (Afanasyev, 2006; Nøst and Børve, 2021). The vortices form a self-propagating dipole pair and

\section{Parameters controlling tidal pumping}

According to Nøst and Børve (2021), the net transport of a tracer through a tidal strait depends primarily on two nondimensional length scales. The first parameter is a purely kinematic one, namely the ratio of the tidal excursion $L_{\mathrm{t}}$ (the expected travel distance of a particle transported by the tidal current) and the length $L_{\mathrm{xs}}$ of the strait:

$L^{*}=\frac{L_{\mathrm{t}}}{L_{\mathrm{xs}}}$.

If the tidal excursion is shorter than the strait $\left(L^{*}<1\right)$, a net transport of properties is not possible. The second non-dimensional length scale reflects the dynamics at play, namely the travel distance of the self-propagating dipole rel- 

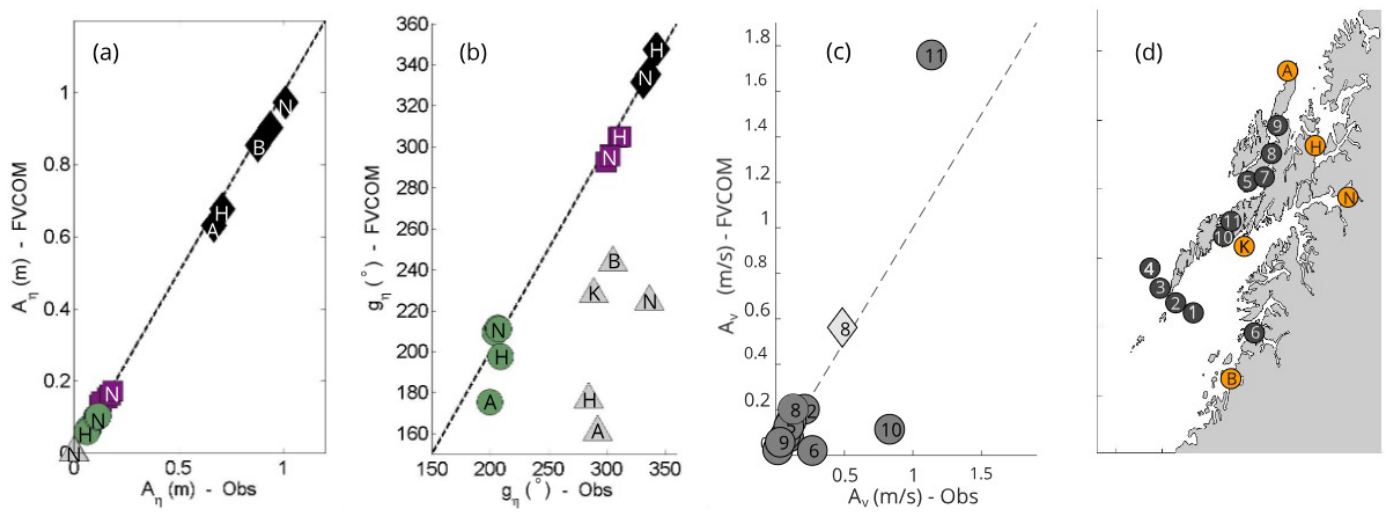

Figure 7. Comparison between modeled and observed tidal properties in Lofoten. Comparisons for the SSH tidal amplitude $A_{\eta}$ and phase shift $g_{\eta}$ are displayed in panel (a) and in panel (b), respectively, for five stations in Lofoten: Andenes (A), Harstad (H), Kabelvåg (K), Narvik (N) and Bodø (B), shown as orange markers in panel (d). The different tidal constituents considered are M2 (black diamonds), K1 (green circles), N2 (purple squares) and S2 (gray triangles). The observations of SSH are collected from the Norwegian Mapping Authority, Hydrographic Service (2021). Panel (c) shows the comparison between tidal current amplitude in the model and from observations collected from Table 3 of Moe et al. (2002). In total, we compare 11 stations in the Lofoten-Vesterålen region, shown as dark gray markers in the right panel (d). We compare the M2 tidal current amplitude from all stations (dark gray circles), and in addition the K1 tidal current amplitude from station 8 (light gray diamond) in Sortlandssundet, since this latter station is in a region where the diurnal tidal current (K1) is known to dominate.

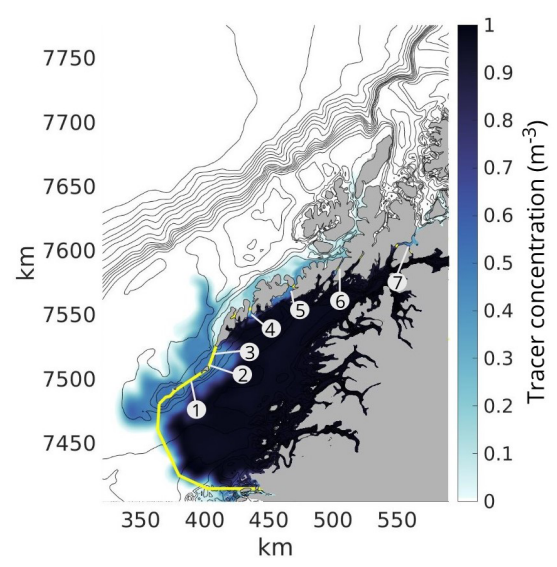

Figure 8. $72 \mathrm{~h}$ average tracer concentration, 2 months after initial tracer release. The yellow line shows the boundary of the initial tracer release area. Inside the yellow boundary, the initial tracer concentration was 1 , while everywhere else the tracer concentration was zero. The contours show the bottom topography. The main straits through the archipelago which will be investigated in this study are (1) Røsthavet, (2) Nordlandsflaget, (3) Moskstraumen, (4) Nappstraumen, (5) Gimsøystraumen, (6) Raftsundet and (7) Tjeldsundet. Note that the numbering does not correspond to the numbering of the stations given in Fig. 7.

ative to the extent of the sink region:

$L_{\mathrm{s}}=\frac{L_{\mathrm{d}}}{R_{\mathrm{S}}}$,

where $L_{\mathrm{d}}$ is the dipole travel distance during one-half of a tidal period and $R_{\mathrm{S}}$ is the sink radius (a measure of the region covered by potential flow on inflow to the strait, Fig. $2 b$ ).
$L_{\mathrm{S}}$ corresponds roughly to the non-dimensional Strouhal number used by Kashiwai (1984) and Wells and van Heijst (2003). If $L_{\mathrm{S}}<1$, the dipole is inside the sink region and will be affected by the potential flow back into the strait. Depending on the self-propagation velocity of the dipole relative to the sink velocity at its positions, a smaller or larger fraction of the dipole will be pulled back into the strait.

While the first non-dimensional parameter, $L^{*}$, is relatively easy to estimate in our study, the second parameter, $L_{\mathrm{S}}$, is more complicated to work with in a realistic setting. $L_{\mathrm{S}}$ depends on the dipole properties and the shape of the sink regions, both of which are affected non-trivially by the kind of complex bathymetry and coastlines present in Lofoten. Therefore, instead of tracking dipole travel distances and estimating sink radii, we here chose to assess the flow asymmetry at the strait openings. In other words, we set out to investigate the extent to which the inflow through a strait opening behaves as potential flow whereas the outflow takes the form of a jet. As such, this relationship is more in line with the original model of Stommel and Farmer (1952) and follows the procedure recommended by Signell and Butman (1992).

To reiterate, the formation of a tidal jet during outflow from a strait requires flow separation which is driven, in part, by the build-up of an adverse pressure gradient. The buildup of an adverse pressure gradient, in turn, requires nonlinear advection of momentum (Signell and Geyer, 1991). So it makes sense to investigate the relationship between nonlinearity and flow asymmetry in the various straits in Lofoten. In a coordinate system where the $x$ axis points along the strait, a truncated form of the along-strait momentum 


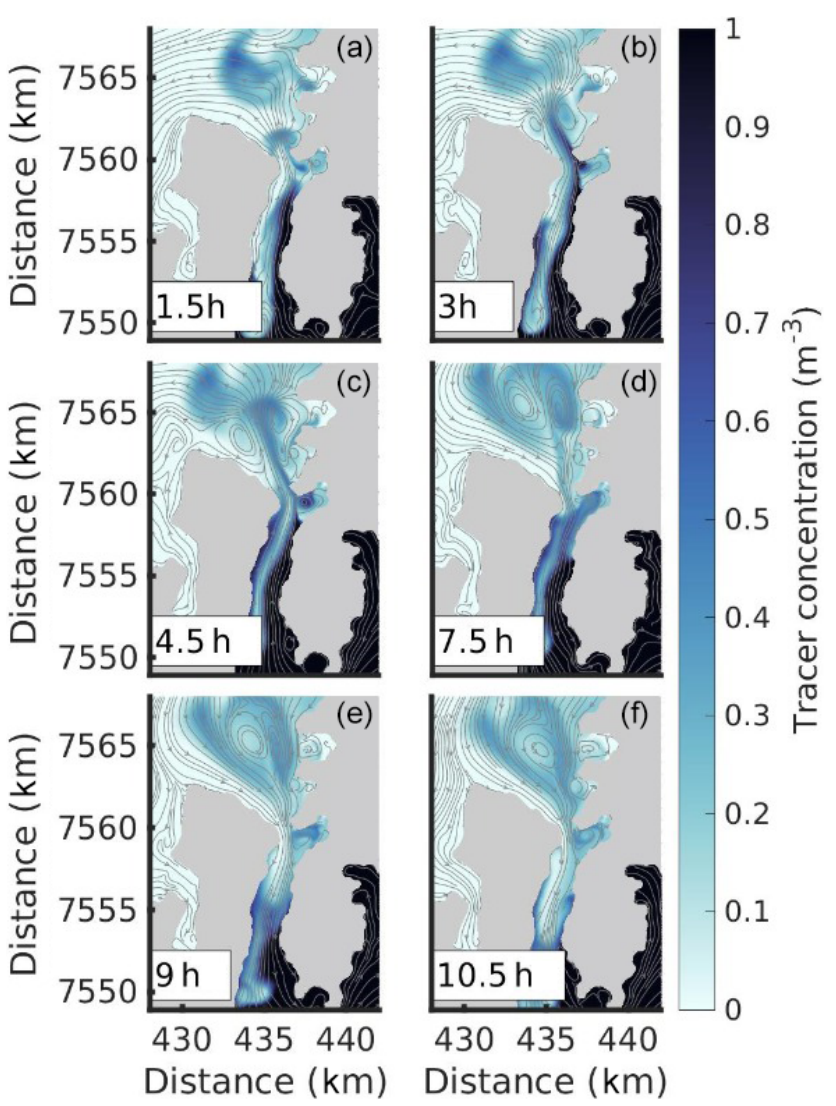

Figure 9. Tracer distribution with corresponding stream-function is displayed for Nappstraumen (4) during the first full tidal cycle in the simulation. The time is given in hours after slack tide after ebb. Panels (a)-(c) are snapshots during northward flow (flood tide), and panels (d)-(f) are snapshots during southward flow (ebb tide).

equation is

$\frac{\partial u}{\partial t}+u \frac{\partial u}{\partial x}=-g \frac{\partial \eta}{\partial x}$

where $u$ is the along-strait velocity, $\eta$ is the sea surface height, and $g$ is the gravitational acceleration. We have ignored cross-strait advection and friction for the arguments to follow (skin friction in our simulations is demonstrably small compared to the time acceleration at tidal frequencies), as well as the Coriolis acceleration which is assumed to be small in the straits considered here. An assessment of the importance of non-linearity in a strait opening can be done by comparing the advection term to the time rate of change of momentum. The advection term itself can be estimated from volume conservation as

$u \frac{\partial u}{\partial x} \sim u_{\mathrm{i}} \frac{u_{\mathrm{i}}}{\Delta x}\left(\frac{A_{\mathrm{i}}}{A_{\mathrm{e}}}-1\right)$,

where $u_{\mathrm{i}}$ is the velocity at the inner, narrow, part of the strait, and $A_{\mathrm{i}}$ and $A_{\mathrm{e}}$ are the cross-sectional areas covered by the current at the inner part of the strait and the strait exit, respectively (Fig. 2). Finally, $\Delta x$ measures the distance over

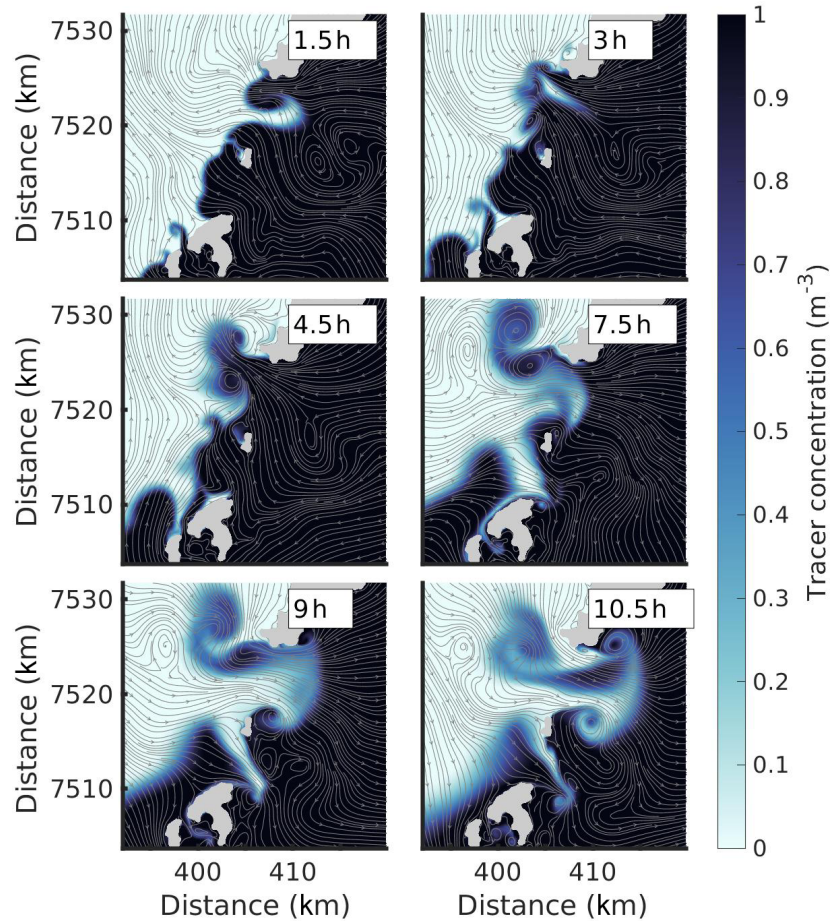

Figure 10. Same as Fig. 9 but for Moskstraumen (3) and Nordlandsflaget (2).

which the change in cross-sectional area takes place. If the tidal current is large and the change in cross-sectional area is large and abrupt (meaning $A_{\mathrm{e}} \gg A_{\mathrm{i}}$ and $\Delta x$ is small), then the non-linear advection will be strong.

The size of the non-linear term compared to the linear time rate of change is then found by dividing Eq. (4) by $u_{\mathrm{i}} / T$, where $T$ is half a tidal period. So we get the non-linearity parameter,

$S_{\mathrm{nl}}=\frac{u_{\mathrm{i}} T}{\Delta x}\left(\frac{A_{\mathrm{i}}}{A_{\mathrm{e}}}-1\right)$.

As shown by the sketch in Fig. 2, the area covered by the jet at the strait exit, $A_{\mathrm{e}}$, can be quite different between inflow and outflow. On inflow the appropriate scale for $A_{\mathrm{e}}$ is the actual width of the strait exit, while on outflow the scale may be that of the jet - if a jet forms. So the maximum strength of non-linearity is best measured on inflow, i.e., using values of $A_{\mathrm{i}}$ and $A_{\mathrm{e}}$ gathered from the strait geometry.

To assess flow asymmetry, we will use the model's pressure or sea surface height field. To understand how flow asymmetry will manifest itself in the pressure field, we again return to the sketch in Fig. 2. If the inflow takes the form of potential flow while the outflow is in the form of a jet (as indicated in the figure), the non-linear pressure gradient across the strait opening (i.e., over distance $\Delta x$ ) will be larger during inflow than during outflow. This observation suggests that the magnitude of the difference in pressure gradient be- 
tween inflow and outflow will be a measure of the asymmetry.

We start by forming normalized pressure gradients across each strait openings:

$\widetilde{\Delta \eta}=\frac{\Delta \eta_{\mathrm{o}} / \Delta x_{\mathrm{o}}}{\Delta \eta_{\mathrm{s}} / \Delta x_{\mathrm{s}}}$,

where $\Delta \eta_{\mathrm{o}} / \Delta x_{\mathrm{o}}$ is the pressure gradient across the opening and $\Delta \eta_{\mathrm{s}} / \Delta x_{\mathrm{s}}$ is the corresponding gradient across the entire strait. The latter should primarily reflect the large-scale pressure gradient, so normalizing by this will help isolate the non-linear contribution to the pressure gradients around the strait exits. The flow asymmetry around a given strait exit is then measured by the magnitude of the difference between $\widetilde{\Delta \eta}$ at flood and ebb tide:

$A_{x \mathrm{o}}=\left|\widetilde{\Delta \eta_{\text {flood }}}-\widetilde{\Delta \eta_{\mathrm{ebb}}}\right|$.

A small value of $A_{x_{0}}$ should indicate negligible flow asymmetry, while a large value should indicate large flow asymmetry and thereby the potential for prominent tidal pumping.

We calculated $\widetilde{\Delta \eta}$ at ebb and flood tide for each M2 tidal cycle at both openings of all the straits shown in Fig. 8. Individual estimates for each strait opening and each phase of the tide (ebb and flood) were then averaged over the whole simulation period. Finally, a mean asymmetry parameter $A_{x \mathrm{o}}$ was calculated for each opening. Since we deal with realistic geometries, the definition of the openings is somewhat subjective. But we tried to apply similar criteria to all strait openings, choosing the most obvious outer strait entrance or exit and the corresponding closest narrow cross section inside. The outer opening would typically be where flow separation and dipole formation could potentially occur and contribute to tidal pumping. An example is the northern exit of Nappstraumen, which is defined to start at the narrow cross-section where the flow separates and dipole forms (see Fig. 9). Corresponding non-linearity parameters $S_{\mathrm{nl}}$ were also estimated over the same openings for each M2 tidal cycle and averaged over these.

The estimates of $A_{x \mathrm{o}}$ and $S_{\mathrm{nl}}$ for the seven straits are shown in Fig. 11. The calculation shows considerable scatter but gives indication that the two parameters are positively correlated. This suggests that most straits that have nonlinear flow dynamics also have a flow asymmetry that may be linked to formation of tidal jets. We made estimates for both openings of each strait since the geometries on the two sides may be widely different. Nappstraumen (4) is the most notable example. At its northern opening, the flood exit, abrupt changes in the coastal geometry causes the flow dynamics to be highly non-linear and asymmetric between flood and ebb. And we see from Fig. 9 that the asymmetry here is closely tied to prominent dipole formation during flood tide. In contrast, at the more gradual opening in the south, non-linearity, dipole formation and asymmetry are much weaker.

The largest non-linearities and asymmetries are found in the northern opening of Nappstraumen (4), in both open-

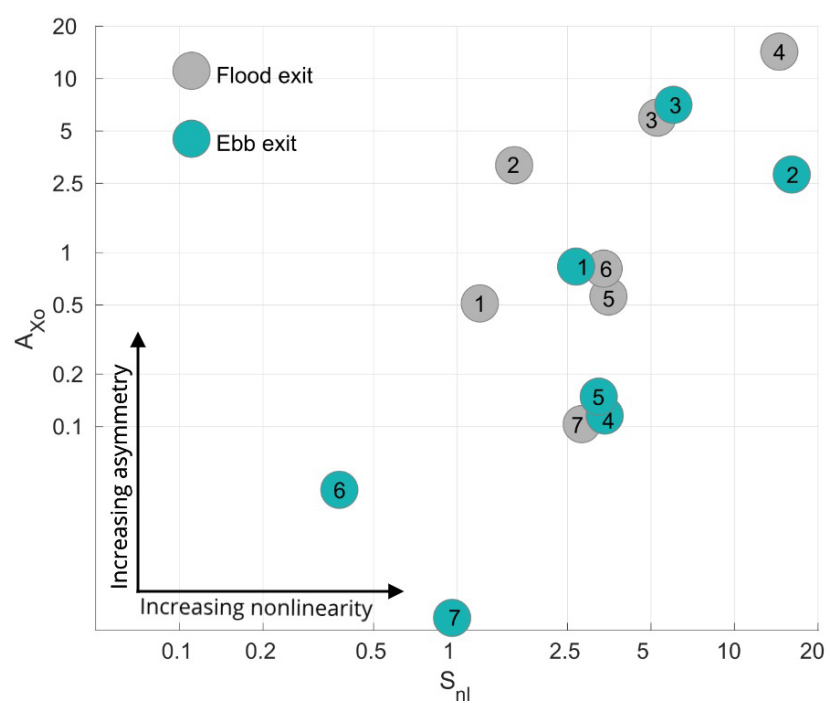

Figure 11. Estimates of the flow asymmetry $A_{x o}$ at the openings of each strait plotted against the non-linearity parameter $S_{\mathrm{nl}}$. Green dots are values at the flood exit (directed out of Vestfjorden), while light gray dots are values at the ebb exits (directed into Vestfjorden). Both parameters are plotted on log scales.

ings of Moskstraumen (3) and in the eastern (ebb) opening of Nordlandsflaget (2). It is interesting to note that the nonlinearity in Røsthavet (1) is comparable to that in the northern (flood) opening of Nordlandsflaget, but that the asymmetry is lower. As it turns out, Røsthavet is the widest strait in the whole region. So although tidal currents are just as large as in Nordlandsflaget and there is actually flow separation here during both phases of the tide (not shown), the vortices formed are too far apart to form a self-propagating dipole and a trailing tidal jet. The longer straits in the north (5-7) all have moderate to low non-linearities and asymmetries. The reason for this is probably that the overall flow dynamics becomes more linear as the strait length increases (Nøst and Børve, 2021). This brings down the current speeds, and hence the non-linearity, in these long straits.

\section{Measuring tidal pumping strength}

To finally evaluate the strength of the tidal pumping, we calculate a tracer transport efficiency for each strait. The transport efficiency $T_{p}^{*}$ is defined as the actual tracer transport through the strait divided by a "transport potential" made up of the time-averaged magnitude of the along-strait velocity $|u|$, the time-averaged mean tracer concentration difference between the two strait openings $\Delta c$ and the strait crosssectional area $A$. So

$T_{p}^{*}=\frac{\iint \overline{u^{\prime} c^{\prime}} \mathrm{d} A}{\overline{\Delta c} \overline{|u|} A}$,

where overbars indicate the time mean and primes indicate perturbations from that mean, so that $\overline{u^{\prime} c^{\prime}}$ is the Reynolds flux 
of $c$. The transport efficiency for a given strait is estimated in the same manner as the non-linearity and flow asymmetry, i.e., by calculating a value for each M2 tidal cycle and then averaging over the whole simulation period.

Figure 12 shows $T_{p}^{*}$ for all straits plotted against asymmetry parameter $A_{x_{0}}$ and the non-dimensional tidal excursion $L^{*}$. The asymmetry parameter for a given strait is the average from the two strait openings. As already discussed, and as seen in panel (a), three straits stand out in terms of flow asymmetry: Nordlandsflaget (2), Moskstraumen (3) and Nappstraumen (4) (where the high value comes from the northern opening). We now see that these are also the three straits with the highest transport efficiency. But even though Nappstraumen has the largest flow asymmetry of all straits, the transport efficiency is notably lower than in Nordlandsflaget and Moskstraumen. The likely reason is tied to the fact that Nappstraumen is a relatively long strait, as can be seen in panel (b). The tidal excursion in Nappstraumen (4) is only twice the strait length, while the excursion in Nordlandsflaget (2) and Moskstraumen (3) is almost 10 times longer than the strait length. Hence, just by considering the strait length, we expect the net effect of flow asymmetries in Moskstraumen and Nordlandsflaget to be larger than in Nappstraumen. Røsthavet (1) is also a short strait, where the tidal excursion is much larger than the strait length. However, in this strait, the flow asymmetry is weak and we thus expect little tidal pumping. We have at present no underlying theory for tidal pumping efficiency as a function of both $A_{x_{0}}$ and $L^{*}$. But since the transport efficiency must depend on both flow asymmetry and short strait length compared to the tidal excursion, we plot $T_{p}^{*}$ against the product of the two parameters in panel (c). The scatter is now reduced and the data from the various straits roughly follow a linear relationship.

In forming the various estimates above, some subjective decisions will impact the results. In particular, the exact value of the asymmetry parameter $A_{x o}$ depends on the location chosen for the inner and outer opening of a strait (to calculate a pressure drop). Complex strait geometries typically make clear-cut choices difficult. Gimsøystraumen (5) is the strait which has the most complex geometry, having two regions where the strait widens in the north (not shown). In Fig. 12 we have therefore shown two estimates of $A_{x \mathrm{o}}$ for this strait, based on pressure differences taken across these two distinct northern openings. The exercises suggest that $A_{x \mathrm{o}}$ for this strait ranges from 0.8 to 5.5 , where the latter value begins to approach the asymmetry of Nappstraumen. We take the span of values in Gimsøystraumen as an upper bound for the general uncertainty in $A_{x \mathrm{o}}$. Raftsundet also has a complex opening in the north; however, the length of this strait is the main limiting factor for net transport by tidal pumping, and the result will not change notably due to the non-linearity parameter. The uncertainty for the other straits, with simpler geometries, is lower. Given this level of uncertainty, we therefore take the above calculations as clear indication that the transport efficiency through the various straits in Lofoten-
Vesterålen are closely linked to the level of flow asymmetry caused by flow separation, dipole and jet formation, and to the length of the straits relative to the tidal excursion.

\subsection{Rectified tidal currents}

The second non-linear process to be assessed is the rectification of oscillating tidal currents around the islands off the southern tip of Lofoten. Residual tidal currents encircling banks and islands have been observed in various places around the world, like Norfolk Island and Georges Bank (Huthnance, 1973; Loder, 1980). The key process, as outlined in the introduction, appears to be net vorticity fluxes generated by vortex stretching and squeezing by oscillating tidal flow over sloping bottom topography - in the presence of some irreversibility, like bottom friction.

In Lofoten, the distortion of the northward-propagating tidal waves produces particularly strong tidal currents across the shallow ridge south of Lofotodden (Fig. 6). Tidal rectification around the island groups located here, Mosken-Værøy and Røst, seems likely. And indeed, a zoom in on this region in Fig. 13 reveals time-mean anticyclonic (clockwise) circulation cells around the islands. There are two distinct circulation cells, one around Røst and another around MoskenVærøy. The circulation cells reach speeds of about 0.2$0.25 \mathrm{~m} \mathrm{~s}^{-1}$, which is similar in magnitude to observed background currents in the region (Mork, 1981). In Moskstraumen, the model's mean current speeds exceed $0.5 \mathrm{~m} \mathrm{~s}^{-1}$, but the strongest flow here is associated with a rectified anticyclone on the inside of that strait - an anticyclone we will return to later. Fig. 13 also shows the time-mean tracer field, revealing that the circulation cells advect low-concentration waters into Vestfjorden northeast of the island groups and high-concentration waters out of the fjord on the southwest sides. So even though much of the net tracer transport south of Lofotodden is due the tidal pumping mechanism investigated above, there is also a contribution driven by anticyclonic mean flows around the islands here. This mechanism appears to be particularly important south of Røst where, it should be noted, there can be no formation of selfpropagating dipoles.

\subsubsection{Vorticity flux and residual currents}

Before doing a quantitative analysis of these currents, we will review some of the relevant theory. One useful starting point (following, e.g., Zimmerman, 1978, 1981) is the vorticity balance derived from the shallow-water equations:

$\frac{\partial \xi}{\partial t}+\nabla \cdot \boldsymbol{u}(f+\xi)=-\nabla \times\left(\frac{\boldsymbol{\tau}_{\mathrm{b}}}{H}\right)$,

where $\xi=\nabla \times \boldsymbol{u}$ is relative vorticity, $f$ is the Coriolis parameter, $\boldsymbol{\tau}_{\mathrm{b}}$ is a bottom stress, and $H$ is the water depth. We have neglected forcing by a surface wind stress and also, for simplicity, lateral viscosity. In the simplified treatment 


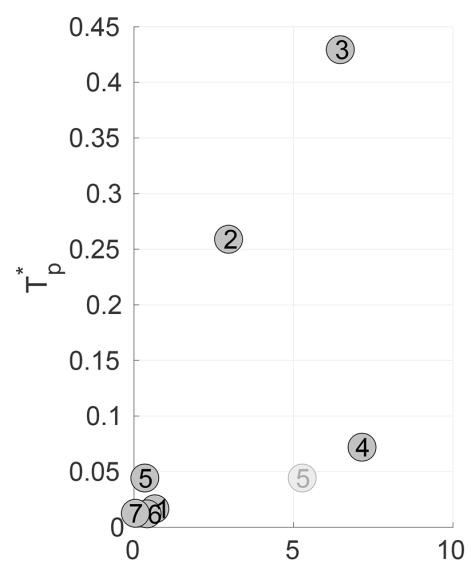

(a) $\mathrm{A}_{\text {xo }}$

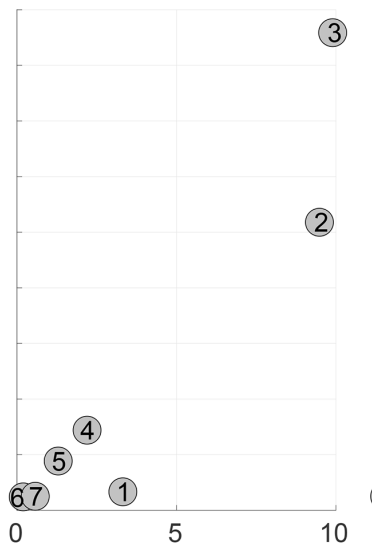

(b) $L^{*}$

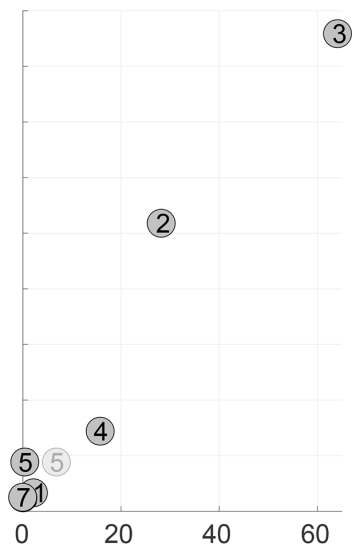

(c) $L * A$ xo

(3)

Figure 12. The tracer transport efficiency $T_{p}^{*}$ plotted against non-dimensional parameters (a) $A_{x_{0}}$, representing flow asymmetry, (b) $L^{*}$, representing strait length and (c) $A_{x \mathrm{o}} L^{*}$, combining the two non-dimensional parameters. Two estimates of $A_{x_{\mathrm{o}}}$ are shown for Gims $\emptyset y s t r a u-$ men (5).
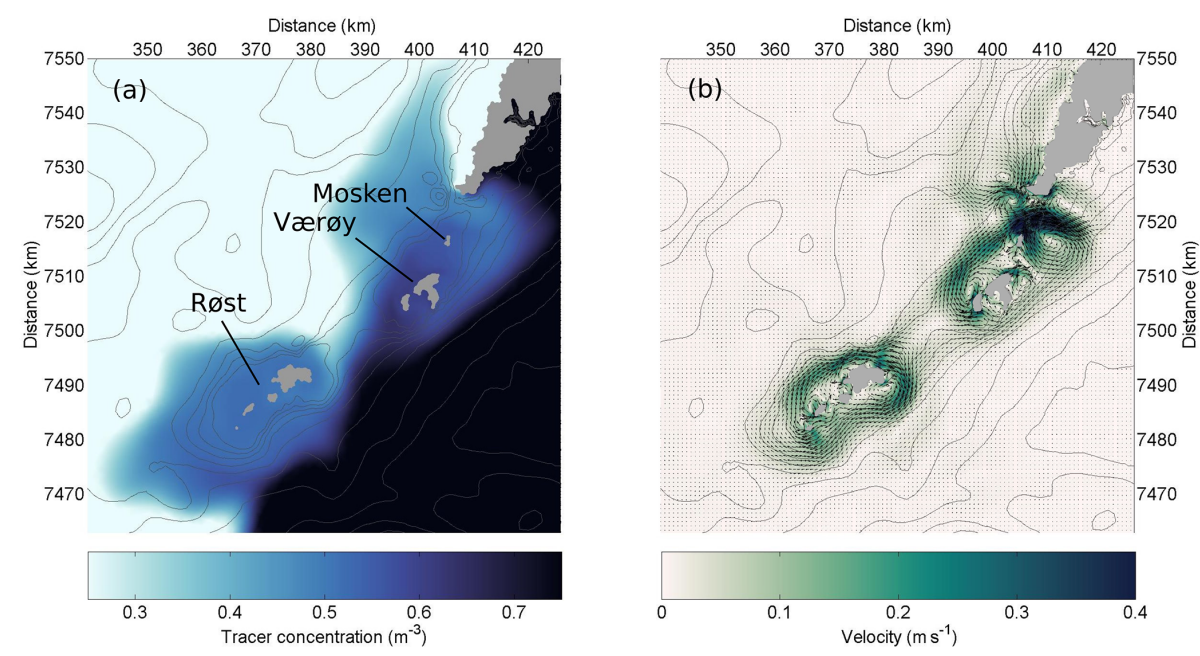

Figure 13. Time-mean tracer concentration (a) and time-mean currents (b) around the southern tip of Lofoten near the end of the simulation. Thin contours show the bottom topography.

below, we will also only consider linear bottom friction, so that $\boldsymbol{\tau}_{\mathrm{b}}=R \boldsymbol{u}$. Finally, we will ignore the sea surface height contribution to the water column thickness, i.e., apply the rigid-lid approximation. Integration of Eq. (9) over the area bounded by a closed depth contour $s$, followed by the use of Green's and Gauss' theorems, gives

$$
\frac{\mathrm{d}}{\mathrm{d} t} \oint \boldsymbol{u} \cdot \hat{\boldsymbol{t}} \mathrm{d} s+\oint \boldsymbol{u}(f+\xi) \cdot \hat{\boldsymbol{n}} \mathrm{d} s=-\oint \frac{1}{H} R \boldsymbol{u} \cdot \hat{\boldsymbol{t}} \mathrm{d} s,
$$

where $\hat{\boldsymbol{t}}$ and $\hat{\boldsymbol{n}}$ are unit vectors tangential (positive clockwise) and normal (positive outwards) to the contour. We now apply the Reynolds decomposition to velocity and vorticity, splitting into means over a tidal cycle and perturbations from such means. If considering the Coriolis parameter to be constant (a very good assumption for the scales considered here), then a time average over a tidal cycle gives the approximate balance

$\frac{\mathrm{d}}{\mathrm{d} t} \oint \overline{\boldsymbol{u}} \cdot \hat{\boldsymbol{t}} \mathrm{d} s+\oint \overline{\boldsymbol{u}^{\prime} \xi^{\prime}} \cdot \hat{\boldsymbol{n}} \mathrm{d} s=-\oint \frac{1}{H} R \overline{\boldsymbol{u}} \cdot \hat{\boldsymbol{t}} \mathrm{d} s$,

where, as before, overbars indicate the time mean and primes indicate perturbations from that mean. The divergent transport of planetary vorticity by the time-mean flow vanishes under the rigid-lid approximation (when integrating over closed depth contours). We have also ignored a term involving transport of mean vorticity by mean currents since this can be assumed to be small for oscillatory tidal forcing. Note that after the time averaging, the time evolution left in Eq. (11) is over scales longer than the fast tidal oscillations. So the expression states that a net Reynolds flux of vorticity out of a closed depth contour ( $H$ is constant) will cause an acceleration of anticyclonic flow around the contour (at 
timescales shorter than $T \sim H / R)$ and, eventually, a timemean anticyclonic flow which balances the vorticity flux with bottom friction.

The total response to arbitrary forcing can be found by Fourier-transforming the above integral equation in time. The expression for each individual Fourier-component becomes

$\oint i \omega \overline{\boldsymbol{u}} \cdot \hat{\boldsymbol{t}} \mathrm{d} s+\oint \overline{\boldsymbol{u}^{\prime} \xi^{\prime}} \cdot \hat{\boldsymbol{n}} \mathrm{d} s=-\oint \frac{R \overline{\boldsymbol{u}}}{H} \cdot \hat{\boldsymbol{t}} \mathrm{d} s$,

where, now, velocity and vorticity are functions of frequency rather than time. Depth $H$ is constant along a closed $s$ contour, and if we assume that $R$ is constant as well, we get an expression for dynamic response of the mean circulation around the contour:

$\oint \overline{\boldsymbol{u}} \cdot \hat{\boldsymbol{t}} \mathrm{d} s=-\frac{\oint \overline{\boldsymbol{u}^{\prime} \xi^{\prime}} \cdot \hat{\boldsymbol{n}} \mathrm{d} s}{R / H+i \omega}$.

So the prediction is a circulation whose magnitude is equal to the integrated vorticity flux scaled by $|R / H+i \omega|$ and whose phase lag is $\phi=\tan ^{-1}(\omega H / R)$. The full response to forcing over a range of frequencies can then be found by solving Eq. (13) for each frequency, followed by an inverse Fourier transform. The time-dependent problem is essentially an $\mathrm{f}$ plane equivalent to that of wind-driven closed- $f / H$ variability studied by Isachsen et al. (2003), but with wind stress forcing replaced by lateral vorticity fluxes.

The primary slow timescale variation in forcing for our problem is the spring-neap cycle. So $\omega_{\mathrm{sn}}=2 \pi / 14.75 \mathrm{radd}^{-1}$. To test the theory with respect to this variation we additionally need to specify a depth level $H$ and a linear friction coefficient $R$. Our FVCOM model uses quadratic bottom drag, but an equivalent linear drag coefficient can be found from $R=C_{\mathrm{d}}|u|$, where $C_{\mathrm{d}}=0.0025$ (the value used in the model) and $|u|$ is a typical current strength. We diagnosed values of 0.29 and $0.23 \mathrm{~m} \mathrm{~s}^{-1}$ for the current strength around Mosken-Værøy and Røst, respectively, and used these to calculate equivalent linear friction coefficients. Then taking a typical depth where the slope is steep, $H=50 \mathrm{~m}$, we calculate theoretical spin-up times of approximately 21 and $14 \mathrm{~h}$ which corresponds to a phase lag $\phi$ of about 0.39 and 0.24 radians, for Mosken-Værøy and Røst, respectively.

We now test these predictions on the time-mean flow cells observed around the islands near the tip of Lofoten. Figure 14 shows the Reynolds vorticity flux out of closed depth contours that wrap around Mosken-Værøy and around Røst. For each contour, a contour-averaged Reynolds flux has been calculated for each sequential M2 tidal cycle. The resulting time series has then been low-pass filtered using a Hanning filter of width equal to four M2 cycles. Finally, for each island group (Mosken-Værøy and Røst) an average has been made over several such closed contours. The calculation clearly reveals a positive vorticity flux out of the contours (towards greater depths) at all times, and this flux is roughly in phase with the spring-neap variations in sea surface height over the region (also shown). Finally, the figure shows the low-passed azimuthal velocity (tangent to a contour) averaged around the same sets of contours. The circulation is anticyclonic and thereby in agreement with the sign of the vorticity flux.

However, the figure also reveals that the two circulation cells respond differently to the spring-neap cycle. The cell around Røst is nearly in phase with the Reynolds flux forcing, with a phase delay of only about half a day - close to the theoretical prediction. But the flow variability around Mosken-Værøy is more erratic and, on average, lagging the forcing by $9-10 \mathrm{~d}$. The amplitude of the spring-neap flow variations around Mosken-Værøy is also smaller than that around Røst even though the amplitude of the Reynolds flux forcing is larger. Taken together, these results indicate that the theory works well at describing the slowly evolving anticyclonic circulation around Røst but that additional dynamics must be considered to understand the cell around MoskenVærøy. We will return to this issue below but will first examine the underlying process that sets up the vorticity flux through these closed depth contours.

\subsubsection{The source of the vorticity flux}

The direction of the vorticity flux may be understood by following a water column that moves periodically up and down a topographic slope, driven by a large-scale tidal potential (Zimmerman, 1978, 1981). Substituting the shallow-water continuity equation into Eq. (9) gives

$\frac{\mathrm{D} \xi}{\mathrm{D} t}=\left(\frac{f+\xi}{H}\right) \frac{\mathrm{D} H}{\mathrm{D} t}-\nabla \times\left(\frac{\boldsymbol{\tau}_{\mathrm{b}}}{H}\right)$,

where $\mathrm{D} / \mathrm{D} t=\partial / \partial t+\boldsymbol{u} \cdot \nabla$ is the total (Lagrangian) time rate of change experienced by the moving water column. Again applying the rigid-lid and $f$-plane approximations, assuming $\boldsymbol{\tau}_{\mathrm{b}}=R \boldsymbol{u}$ and now splitting up the friction term, gives

$\frac{\mathrm{D} \xi}{\mathrm{D} t}=\left(\frac{f+\xi}{H}\right) \boldsymbol{u} \cdot \nabla H+\frac{R}{H^{2}} \boldsymbol{u} \times \nabla H-\frac{R}{H} \xi$,

from which we can see that relative vorticity of the column has two source terms and one sink term. The first term on the right-hand side (RHS) is vorticity production due to stretching or squeezing of the water column by flow over uneven bottom topography. If $f+\xi>0$ motion towards deeper (shallower) water induces positive (negative) relative vorticity perturbations. The second term is production of vorticity due to flow along a sloping bottom and often referred to as a bottom friction torque. The last term on the RHS is a loss of vorticity to bottom friction. 


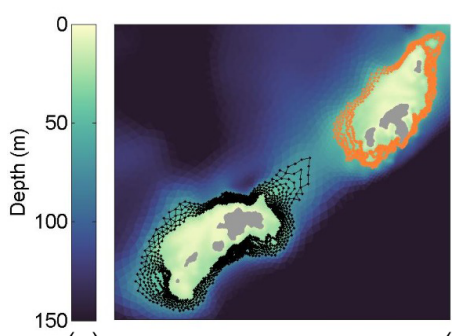

(a)

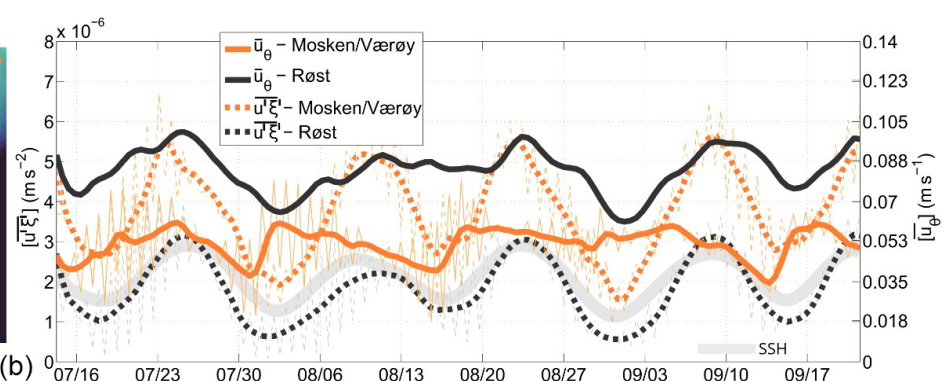

(b) $0_{07 / 16}^{0} \begin{array}{llllllllll}07 / 23 & 07 / 30 & 08 / 06 & 08 / 13 & 08 / 20 & 08 / 27 & 09 / 03 & 09 / 10 & 09 / 17 & 0\end{array}$

Figure 14. Reynolds vorticity flux and tangential flow calculated around closed depth-contours encircling Røst (black curves) and around Mosken-Værøy (orange curves), shown in panel (a). Panel (b) shows time series the mean Reynolds vorticity flux $\left(\overline{u^{\prime} \xi^{\prime}} \cdot \hat{\boldsymbol{n}}\right.$, dashed lines) out of closed depth contours that wrap around Mosken-Værøy (orange) and around Røst (black), and azimuthal velocity $\left(\bar{u}_{\theta}=\overline{\boldsymbol{u}} \cdot \hat{\boldsymbol{t}}\right.$, solid lines), both averaged around the same closed contours. All quantities shown by thick lines have been smoothed over four M2 cycles and also averaged over a set of closed contours between 30 and $70 \mathrm{~m}$. The thin curves with brighter colors in the background are velocities averaged over one M2 tidal cycle. Sea surface height fluctuations (thick gray line) over southern Lofoten are also shown.

If we assume $|\xi| \lesssim f$ (see, e.g., Table 1 of Zimmerman, 1978), then the sizes of the two production terms are

$$
\begin{gathered}
\frac{(f+\xi)}{H} \boldsymbol{u} \cdot \nabla H \sim \frac{f U h^{\prime}}{D L}, \\
\frac{R}{H^{2}} \boldsymbol{u} \times \nabla H \sim \frac{R U h^{\prime}}{D^{2} L},
\end{gathered}
$$

where $U$ is tidal current amplitude, $D$ is mean water depth and $h^{\prime}$ and $L$ are the height and length scales of the topographic feature. So the relative size of the two terms scales as $f D / R$. Using typical values for Mosken-Værøy and Røst as above $\left(D \sim 50 \mathrm{~m}, R=6 \times 10^{-4}\right.$ and $9 \times 10^{-4} \mathrm{~m} \mathrm{~s}^{-1}$, and $f \sim$ $10^{-4} \mathrm{~s}^{-1}$ ), gives $f D / R \sim 6$ and 12 for Mosken-Værøy and Røst, respectively. Here, we have picked a depth value which corresponds to the steeper parts of the slope (where vorticity generation by either mechanism can be assumed to be most relevant) and assumed that the along-slope and crossslope velocity components are of similar magnitude. One might intuitively expect the along-slope component to be larger than the across-slope component, but perhaps primarily for longer-timescale (subinertial) motions. Diagnosing the model fields around Mosken-Værøy and Røst showed that the ratio between the two is only about 1.2-1.4 for the tidal motions considered here (calculated for the depth contours in Fig. 14). This suggests that vorticity production by flow up and down topography is quite a bit larger than production by bottom friction torque. If $|\xi|>f$ the production term by squeezing and stretching of the water column becomes increasingly larger compared to production of bottom friction torque for the same depth. Even though the latter term is not necessarily negligible, we will omit it in the following for simplicity, resulting in the approximate expres- sion

$$
\begin{aligned}
\frac{\mathrm{D} \xi}{\mathrm{D} t} & =\left(\frac{\xi+f}{H}\right) \boldsymbol{u} \cdot \nabla H-\frac{R}{H} \xi \\
& =\left(\frac{\xi+f}{H}\right) \frac{\mathrm{D} H}{\mathrm{D} t}-\frac{R}{H} \xi,
\end{aligned}
$$

or, cast in terms of potential vorticity (PV),

$\frac{\mathrm{D}}{\mathrm{D} t}\left(\frac{f+\xi}{H}\right)=-\frac{R}{H^{2}} \xi$.

In the absence of bottom friction, PV is conserved, and the relative vorticity of a water column will only be a function of depth (on the $f$ plane). So as the water column oscillates up and down a sloping bottom, it will gain just as much negative (anticyclonic) vorticity on its way up the slope as it gains positive (cyclonic) vorticity on its way down the slope. The net vorticity transport by the column across a given depth contour will therefore be zero. Crucially, friction changes this since the column will then lose some negative vorticity over shallow waters and lose some positive vorticity over deep waters. Thus, on passing any given depth contour the column will carry an excess of positive vorticity on its way towards deep waters and an excess of negative vorticity on its way towards shallow water. The end result is a transport of positive vorticity towards deep waters. A simple sketch of the rectification process is shown in Fig. 3 and a simplified mathematical model is offered in the Appendix.

The net effect after integrating over the movement of many such water columns is a positive relative vorticity flux towards deep regions. Hence, Eq. (11) predicts anticyclonic currents around a bank or island, and this is indeed what we observe in Figs. 13 and 14. It is worth noting that the vorticity flux is down the large-scale background PV gradient $q_{\mathrm{s}}=f / H$. So when we ignore Reynolds transport of layer thickness (in line with the rigid-lid approximation), the process is qualitatively consistent with the idea of potential enstrophy dissipation via a down-gradient PV flux (Bretherton and Haidvogel, 1976; Ou, 1999). 
The magnitude of the rectified current depends on the steepness of the topographic slope and the strength of the cross-slope tidal oscillations (Zimmerman, 1978; Loder, 1980; Wright and Loder, 1985). From the scaling argument above, we found that the main driver of rectification is the generation of relative vorticity by advecting water columns up and down the bottom topography. Thus, by identifying the regions of max potential for generation of relative vorticity by cross-slope tidal currents, we can identify the areas where tidal rectification is to be expected. To look at this, we ignore the effect of bottom friction, leaving

$\frac{\mathrm{D} \xi}{\mathrm{D} t}=\frac{f+\xi}{H} \frac{\mathrm{D} H}{\mathrm{D} t}$.

Hence, the relative vorticity change $\xi^{\prime}$ experienced by a water column forced across variable topography scales as

$\xi^{\prime}=\frac{f+\xi_{0}}{H_{0}} h^{\prime}$

where $\xi_{0}$ and $H_{0}$ are initial vorticity and depth, respectively, and $h^{\prime}$ is the topographic variation. If we assume a constant bottom slope $\Delta H=\alpha$, then $h^{\prime}=\alpha L$ where $L$ is the lateral excursion of the water column. A topographic length scale $L_{\mathrm{B}}=H_{0} / \Delta H$ can then be defined as that which gives a depth excursion equal to the initial depth, or $H_{0}=\alpha L_{\mathrm{B}}$. By Eq. (20), such an excursion would produce the maximum relative vorticity deviation and hence the maximum potential for rectified currents. The actual lateral excursion experienced by parcels is given by the tidal excursion $L_{\mathrm{T}}=$ $\int \boldsymbol{u} \cdot \hat{\boldsymbol{n}} \mathrm{d} t$ where, again, $\hat{\boldsymbol{n}}$ points down the topographic gradient and where the integral is taken over half a tidal cycle. Thus, $h^{\prime}=\alpha L_{\mathrm{T}}$. If $L_{\mathrm{T}} \ll L_{\mathrm{B}}$ then vorticity change will be small since the full potential for stretching/compression is not utilized. And if $L_{\mathrm{T}} \gg L_{\mathrm{B}}$ then the net vorticity change integrated over half a tidal cycle will likely also be small due to sign reversals as the column is advected up and down topographic "bumps". Intuitively then, and as verified numerically by Zimmerman (1978), one expects that the largest potential for the generation of rectified currents where $L_{\mathrm{T}} \sim L_{\mathrm{B}}$ (see also Loder, 1980; Polton, 2015).

The ratio between time-mean $L_{\mathrm{T}}$ and $L_{\mathrm{B}}$ off the tip of Lofoten is shown in Fig. 15. The topographic scale $L_{\mathrm{B}}$ has been calculated from bathymetric data and the tidal excursion $L_{\mathrm{T}}$ has been estimated using the mean M2 tidal current amplitudes across topography. The figure also shows the time-mean flow, and there is clear indication that the rectified currents around Mosken-Værøy and around Røst are most pronounced where $L_{\mathrm{B}} / L_{\mathrm{T}} \gtrsim 1$. We take this as supportive evidence that the rectified currents around these islands are driven by oscillating flows over topography subject to weak bottom friction. Figure 16 shows the strength of the rectified currents around the above-studied closed $\mathrm{H}$ contours as a function of $L_{\mathrm{T}} / L_{\mathrm{B}}$, where $L_{\mathrm{T}}$ is now allowed to vary as a function of time (i.e., with the spring-neap cycle). Around

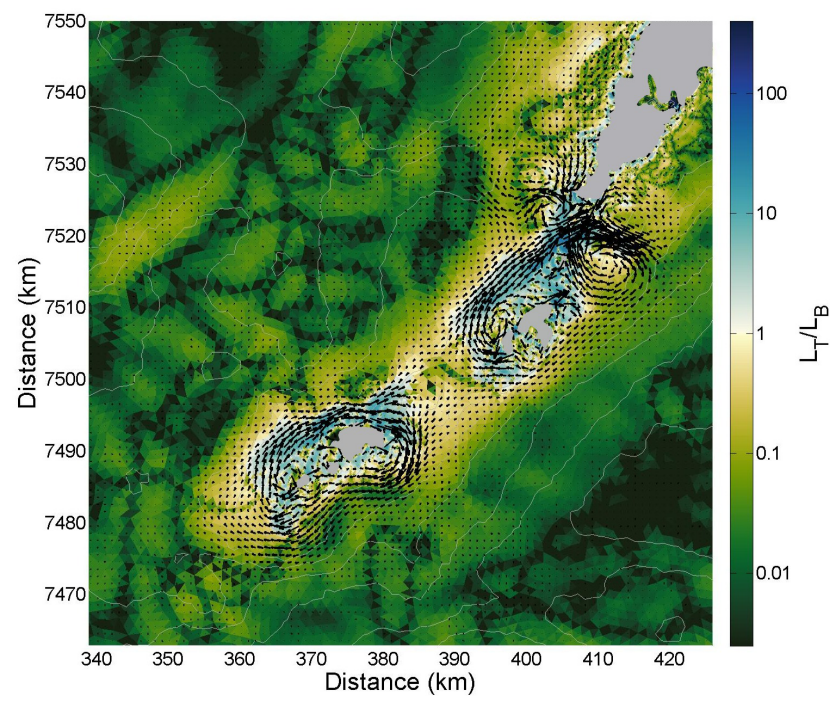

Figure 15. The ratio $L_{\mathrm{T}} / L_{\mathrm{B}}$ around southern Lofoten. Arrows show the time-mean rectified flow while white contours show bottom topography.

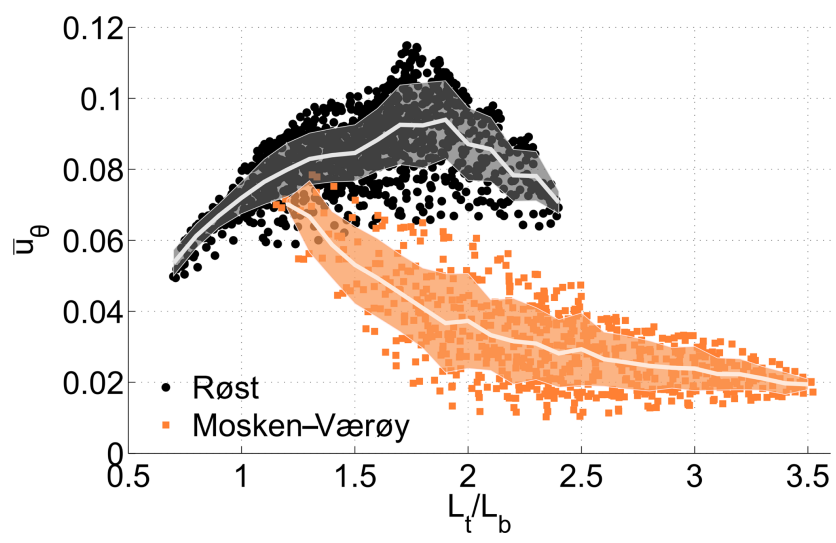

Figure 16. The strength of the rectified tidal currents around Røst (black dots) and around Mosken-Værøy (orange dots) are plotted against the ratio $L_{\mathrm{T}} / L_{\mathrm{B}}$ averaged around closed depth contours. Each dot corresponds to a time-mean velocity averaged over one tidal cycle. The bright thicker lines show the mean values of the residual tidal current corresponding to a given value of $L_{\mathrm{T}} / L_{\mathrm{B}} \pm$ 0.1 . Shading indicates 1 standard deviation around the mean.

Røst, residual currents attain a maximum for $L_{\mathrm{T}} / L_{\mathrm{B}} \sim 1.75$, with declining strengths for both smaller and larger values of the ratio. This is in agreement with theory. In contrast, the plot does not show any optimal value of $L_{\mathrm{T}} / L_{\mathrm{B}}$ for the flow around Mosken-Værøy. The residual current strength here instead decreases monotonically with larger values of the ratio. As we will see next, the reason for the anomalous behavior around these islands turns out to be finite-amplitude non-linear effects. 


\subsubsection{Non-linear dynamics around Mosken-Værøy}

The sign of the residual currents around Mosken-Værøy is in agreement with the sign of the Reynolds vorticity flux across the closed depth contours there. But, as seen above, the time variability does not correlate trivially with the spring-neap variations in the vorticity flux. So additional dynamical processes must be at play here and, as indicated by Fig. 13, a semi-persistent anticyclone southeast of Moskstraumen is likely the culprit. During each ebb tide, when the flow entering Vestfjorden through Moskstraumen separates from the coastline, a dipole is formed, as seen in Fig. 10. After flow reversal, the cyclonic half of the dipole is typically drawn back into Moskstraumen, whereas the anticyclonic vortex remains on the southeastern side of the strait. The position of the anticyclone varies somewhat over time, but it is consistently strengthened by new vortex formation during each ebb phase.

Figure 17 shows streamlines of the time-mean flow in the vicinity of Mosken-Værøy. The streamlines that wrap around these two islands generally follow depth contours. But the anticyclone east of Mosken is strong enough to break topographic steering in the northeast. Streamlines that encircle the island group detach from topography just north of Mosken to wrap around the anticyclone. The closed depth contours around Mosken-Værøy thus pass through the southwest flank of the anticyclone, so that currents from the vortex are here in the opposite direction compared to the rectified currents along the rest of the contours.

In essence, the strong anticyclone has deformed the geostrophic contours guiding the time-mean flow, and the integral analysis of Eq. (13) needs to follow this modified path. Figure 17 shows the vorticity flux and circulation around a streamline that wraps around the island group and the anticyclone. Following this modified integration path shows that the circulation cell is indeed in near phase with the Reynolds flux forcing. The figure also shows the average azimuthal velocity integrated along an incomplete stretch of the original depth contours, south and west of the island group. The flow here is also in near phase with the spring-neap variations. So the circulation cell around the island group is forced by Reynolds vorticity fluxes, by the mechanism outlined above. But the strong non-linearity in Moskstraumen makes the dynamics more complex than around the island of Røst to the south.

\section{Summary and conclusions}

While the tides in Lofoten-Vesterålen are well known to be strong and vigorous, dominating the short-term ocean dynamics, particularly in straits and around topographic features (Gjevik et al., 1997; Moe et al., 2002), their contribution to long-term transport has gained relatively little attention. The one notable exception is Moskstraumen, which is recognized as one of the main transport routes out of Vestfjorden (Ommundsen, 2002; Vikebø et al., 2007; Opdal et al., 2008; Lynge et al., 2010). Our unstructured-grid tidal simulations of the entire Lofoten-Vesterålen region confirm that Moskstraumen and, more generally, the region off the southern tip of the Lofoten archipelago is indeed the primary location for tidal dispersion in this key spawning region for the northeast Arctic cod. The main focus of this study, however, has not been quantification of transport but rather the identification of the underlying non-linear dynamics responsible for dispersion and transport.

The flexible model grid, and the ability it offers to increase resolution in key regions, allowed us to confirm that tidal pumping, caused by flow separation and vortex dipole formation at the openings of the many straits in LofotenVesterålen, is a near-ubiquitous process here. But geometry and flow conditions around each strait are different, and the tracer transport due to tidal pumping varies greatly. Strong non-linearity due to high flow speeds and abrupt strait openings, as well as short strait lengths, appears to be the explanation for why Moskstraumen and Nordlandsflaget have the highest tidal transport efficiencies in the region. The longer straits further north all have lower pumping efficiencies. But notable pumping also takes place in Nappstraumen and Gimsøystraumen.

Tidal pumping, particularly in relation to tidal flushing of estuaries and nearshore regions, have been widely studied elsewhere. Certainly, the formation of dipole vortices is observed many places where prominent tidal currents exit narrow straits, for example, in Aransas Pass (USA), Messina Strait (Italy) and the Great Barrier Reef (Australia) (Whilden et al., 2014; Cucco et al., 2016; Delandmeter et al., 2017). Cucco et al. (2016) show that the strong tidal currents and subsequent pumping are important for water exchange and for modifying the thermohaline properties in two large subbasins of the Western Mediterranean Sea. We thus consider it possible that tidal pumping in Lofoten and Vesterålen not only contributes to transport of dynamically passive particles such as cod eggs but is also important for the transport of freshwater out of the large Vestfjorden embayment, thereby modifying the thermohaline properties here.

Our simulation also revealed non-linear rectification of tidal oscillations, leading to the generation of time-mean anticyclonic circulation cells around the island groups of Mosken-Værøy and Røst off the southern tip of the archipelago. From our knowledge, tidal rectification in southern Lofoten has neither been investigated nor recognized before. But the rectification in our model results seems to be in agreement with well-established theory of vorticity fluxes driven by cross-topographic tidal oscillations in the presence of bottom friction. The model predicted rectified current speeds up to $0.2 \mathrm{~ms}^{-1}$, values that are comparable with observed background currents in this region. The circulation cell around Røst appears to be a particularly important 


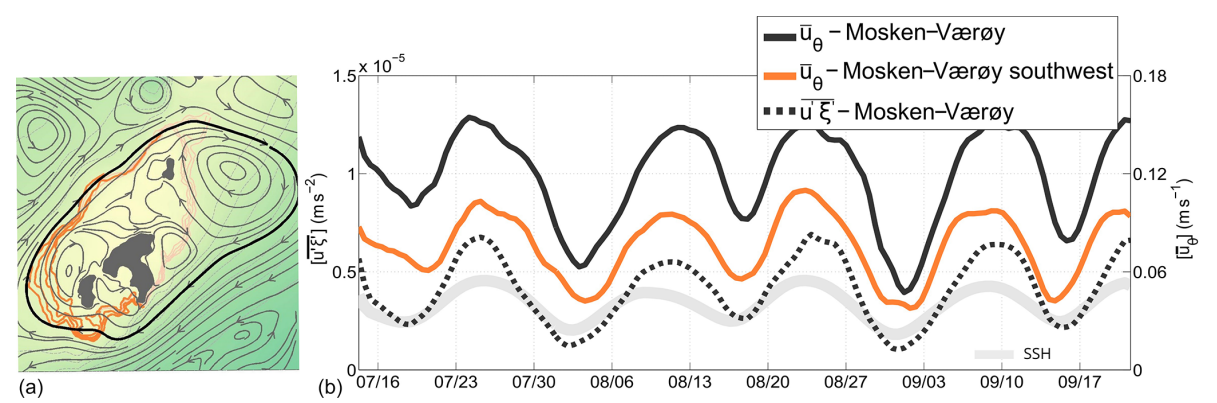

Figure 17. Close-up of the flow field around Mosken-Værøy. Panel (a) shows time-mean streamlines (gray contours with arrow heads) as well as a set of depth contours that wrap around the island group (orange contours). Panel (b) shows the Reynolds vorticity flux (dashed black line) through one closed streamline which wraps around the island group and the anticyclone east of Mosken (thick black contour in a). Also shown is the circulation around the same contour (solid black line) as well as the circulation along an incomplete depth contour south and west of the island group (solid orange line). The sea surface height variation is shown with a thick light gray line.

and hitherto unknown mechanism for tracer transport around the southern tip of the archipelago.

We find that the potential for tidal rectification can be evaluated through the relation $L_{\mathrm{T}} / L_{\mathrm{B}}$, where values near 1 indicate prominent rectification (Loder, 1980). The residual currents around the island groups in southern Lofoten thus appear to be governed by dynamics similar to what is observed around Georges Bank (Loder, 1980; Limeburner and Beardsley, 1996; Chen et al., 2001). There, the residual currents encircling the bank in a clockwise fashion are of similar strength to the flow we model around Røst and MoskenVærøy $\left(0.2-0.3 \mathrm{~m} \mathrm{~s}^{-1}\right)$. Using the values provided in Table 1 in Loder (1980), we find that on the northwestern and northern sides of Georges Bank $L_{\mathrm{T}} / L_{\mathrm{B}} \sim 1$, equivalent to what we find for the islands of southern Lofoten.

The non-linear tidal dynamics studied here, particularly flow separation and dipole formation, occurs on small spatial scales. In studying idealized model simulations of tidal pumping, Nøst and Børve (2021) found that a grid resolution of $50 \mathrm{~m}$ along the coast was necessary to realistically capture flow separation in the viscous boundary layer but maybe not sufficient to properly resolve the vortices that form at the separation point. More specifically, the study showed that the vortices consistently formed near the smallest scale that could be resolved by that model. Lynge et al. (2010) also found that particle dispersion in realistic model simulations of Moskstraumen was highly sensitive to grid resolution and that a resolution of 50-100 $\mathrm{m}$ was needed for obtaining what they reported to be realistic dispersion rates. This is in line with results reported by Delandmeter et al. (2017), who simulated dipole formation through straits cutting through a line of islands separated by $1-2 \mathrm{~km}$, i.e., straits with geometries comparable to Moskstraumen and Nordlandsflaget. The authors modeled the flow using grid resolutions up to $50 \mathrm{~m}$, which largely captured the eddy formation and flow pattern. In our unstructured-grid model, most of the straits had a grid resolution of 30-50 m near the coastline, so the underlying mechanisms of flow separation and vortex formation were fairly well resolved. However, due to computational constraints, we had to decrease the resolution considerably away from the straits and coastlines. So since the properties and behavior of the dipoles might be influenced by grid resolution along their travel path, we expect our simulations as well to be hampered by resolution issues. Thus, we refrained from making quantitative estimates of transport parameters like relative dispersion and lateral diffusivities, which are known to be sensitive to model resolution (Geyer and Signell, 1992; LaCasce, 2008; Lynge et al., 2010).

Our simulations were also limited by their 2-D nature. A 2-D configuration was chosen to help isolate non-linear lateral tidal dynamics, but the model was thus unable to account for baroclinic effects. Such effects include the generation of hydraulic jumps and vertical mixing around strait openings (Lynge et al., 2010), the establishment of density fronts around the rectification cells (Ou, 2000) and also bottom intensification of such rectified flows, with concomitant vertical circulation cells around banks and islands (Maas and Zimmerman, 1989; White et al., 2005, 2007). So, in reality, baroclinic flow dynamics will also impact tracer transport, both vertically and laterally. But some key features of the model's lateral flow dynamics still appear to be robust. Flow separation and dipole formation in Moskstraumen, for example, are largely in agreement with observational evidence, seen, e.g., in satellite data (Fig. 4). The suggestion that there are anticyclonic time-mean currents around the island groups of Mosken-Værøy and Røst, generated by tidal rectification, is however worthy of a new and dedicated observational study.

Notwithstanding model limitations, the present study supports previous claims that tides are an important contributor to the transport of drifting material, and in particular northeast Arctic cod eggs and larvae, out of Vestfjorden. Even if the main transport routes due to tides coincide with transport routes following the mean flow, i.e., through Moskstraumen and south of Røst, the net transport could potentially be significantly enhanced when non-linear tidal dynamics are 
present. In truth, the connectivity between the inner and outer shelf likely relies on the interaction between tidal dispersion and transport by the time-mean currents (Ommundsen, 2002). Additionally, our study suggests that tidal pumping through straits further north along the archipelago, in particular Nappstraumen and Gimsøystraumen, could provide alternative transport routes to the shelf. In an ongoing study, we analyze 3-D unstructured-grid simulations driven by realistic atmospheric, river and lateral boundary forcing. The aim there is to investigate the relative importance of tidally induced transport of cod eggs and larvae compared to, or in combination with, other transport processes in this region. The more realistic 3-D study will hopefully also add to the general understanding of the role of non-linear tidal dynamics in similar coastal regions, with the ultimate aim of providing more accurate transport estimates of fish eggs and larvae, as well as pollutants, nutrients and other properties that affect the coastal ecosystem.

\section{Appendix A: A one-dimensional model of tidal rectification}

We consider the Lagrangian time evolution of a water column subject to linear bottom friction:

$\frac{\mathrm{D}}{\mathrm{D} t}\left(\frac{f+\xi}{H}\right)=-\frac{1}{H} \nabla \times \frac{R \boldsymbol{u}}{H}$.

For simplicity we will assume that the RHS is dominated by velocity gradients, giving

$$
\frac{\boldsymbol{D}}{\boldsymbol{D} t}\left(\frac{f+\xi}{H}\right)=-\frac{R}{H^{2}} \xi \text {. }
$$

As formally laid out by, e.g., Zimmerman (1978), we now consider the situation where the column is forced to move up and down topography by tidal currents that are dictated by remote dynamics. Thus, $H=H(t)$ is specified. The relative vorticity $\xi$ however is assumed to be a local response to the vortex compression/stretching by this movement across topography and to the effects of friction.

Equation (A2) can be written out to give a first-order ordinary differential equation:

$\frac{\mathrm{D} \xi}{\mathrm{D} t}-\left(\frac{1}{H} \frac{\mathrm{D} H}{\mathrm{D} t}-\frac{R}{H}\right) \xi=\frac{f}{H} \frac{\mathrm{D} H}{\mathrm{D} t}$.

This takes the form of a forced equation for $\xi$ with damping, where the damping coefficient is non-constant. We now define

$p(t)=\frac{1}{H} \frac{\mathrm{D} H}{\mathrm{D} t}-\frac{R}{H}$,

and multiply Eq. (A3) by $\exp \left(-\int p(t) \mathrm{d} t\right)=$ $\exp \left(\int R / H \mathrm{~d} t\right) / H$ before integrating in time. The expression becomes (after applying integration by parts to both

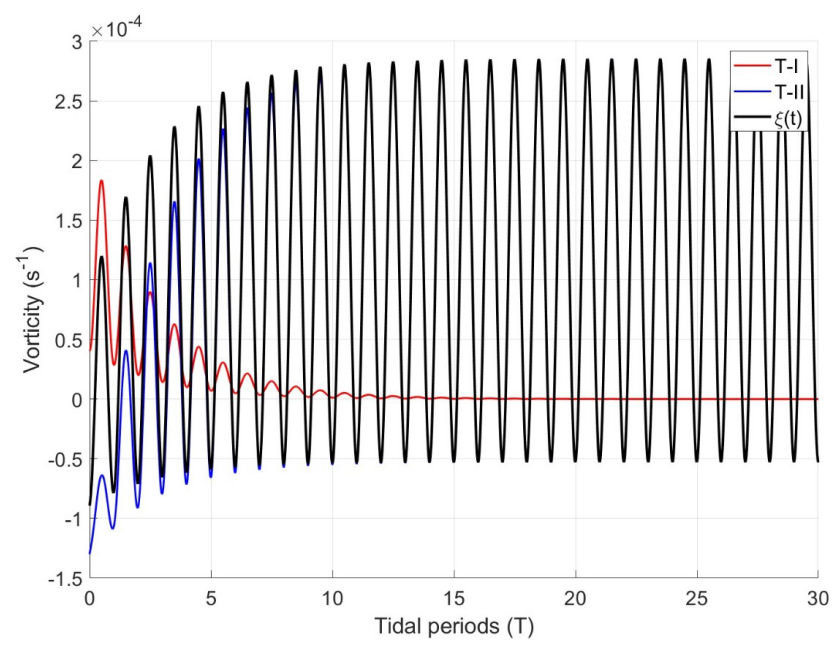

Figure A1. Vorticity evolution of a water column forced to oscillate over a linear bottom slope, for $\xi_{0}=0, H_{0}=500 \mathrm{~m}, \alpha=0.1, A=$ $0.5 \mathrm{~m} \mathrm{~s}^{-1}, \omega=1.4 \times 10^{-4} \mathrm{rad} \mathrm{s}^{-1}$ (for M2) and $R=0.003 \mathrm{~m} \mathrm{~s}^{-1}$. The red line is the transient solution (term T-I in Eq. A6), the blue line is the statistically steady solution (term T-II), and the black line is the full solution.

sides):

$$
\begin{aligned}
\int_{0}^{t} \frac{\mathrm{D}}{\mathrm{D} t}\left(\frac{\xi}{H} e^{\int R / H \mathrm{~d} t}\right) \mathrm{d} t & =-\int_{0}^{t} \frac{\mathrm{D}}{\mathrm{D} t}\left(\frac{f}{H} e^{\int R / H \mathrm{~d} t}\right) \\
& +\int_{0}^{t} \frac{f R}{H^{2}} e^{\int R / H \mathrm{~d} t} \mathrm{~d} t,
\end{aligned}
$$

and the solution is

$$
\begin{aligned}
\xi(t) & =\underbrace{\left(\xi_{0}+f\right) \frac{H}{H_{0}} e^{-\int_{0}^{t} R / H \mathrm{~d} t}}_{\mathrm{T}-\mathrm{I}} \\
& -\underbrace{f\left[1-R H e^{-\int_{0}^{t} R / H \mathrm{~d} t} \int_{0}^{t} \frac{1}{H^{2}} e^{\int_{0}^{t} R / H \mathrm{~d} t} \mathrm{~d} t\right]}_{\mathrm{T}-\mathrm{II}},
\end{aligned}
$$

where $\xi_{0}$ and $H_{0}$ are the relative vorticity and bottom depth at $t=0$. Here, the term T-I describes an exponentially decaying adjustment from the initial state, whereas the term T-II describes a part of the solution which achieves statistical equilibrium with the forcing. After a few tidal cycles $\exp \left(-\int_{0}^{t} R / H \mathrm{~d} t\right) \rightarrow \exp (-\gamma t)$, where $\gamma$ is an inverse timescale for the adjustment from initial to steady state. As seen, this spin-up timescale depends on the friction coefficient and the bottom depth variations experienced by the column.

We now evaluate Eq. (A6) numerically for a very simplified configuration consisting of forced flow over a linear topography, i.e., for $H=H_{0}-\alpha r(t)$, where $\alpha$ is the bottom 

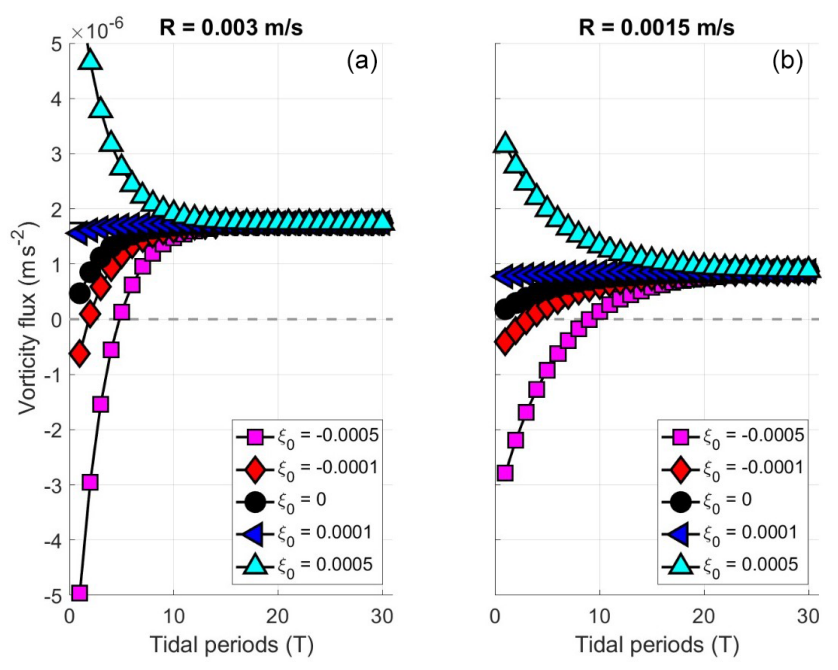

Figure A2. Vorticity flux averaged over an integral number of tidal period as a function of time, for the solution of Eq. (A6). Positive values indicate a vorticity flux towards deep waters. Panels (a) and (b) show results for $R=0.003 \mathrm{~m} \mathrm{~s}^{-1}$ and $R=0.0015 \mathrm{~m} \mathrm{~s}^{-1}$, respectively, starting from five different initial vortices $\xi_{0}$. The other parameters are as in Fig. A1.

slope and $r(t)$ is the cross-slope excursion from $r(t=0)$ where $H=H_{0}$. For added simplicity, we assume a sinusoidal cross-slope tidal current, $v_{r}(t)=A \cos (\omega t)$ for tidal amplitude $A$ and frequency $\omega$, so that $H(t)$ also becomes sinusoidal. A solution, for parameter choices $\xi_{0}=0, H_{0}=$ $500 \mathrm{~m}, \alpha=0.1, A=0.5 \mathrm{~m} \mathrm{~s}^{-1}, \omega=1.4 \times 10^{-4} \mathrm{rad} \mathrm{s}^{-1}(\mathrm{M} 2)$ and $R=0.003 \mathrm{~m} \mathrm{~s}^{-1}$, is shown in Fig. A1. The relative vorticity of the water column reaches a statistically steady state after about 10 tidal periods (about $5 \mathrm{~d}$ for M2 tidal forcing), with this corresponding to two to three $e$-folding scales. The column then has positive and negative relative vorticity over deep and shallow parts, respectively. The amplitude is largest over deep parts due to the inverse dependence of depth in the friction term (see Eq. A2). Interpolating this vorticity field to mid-depth $\left(H=H_{0}\right)$ and taking the product of the velocity gives the Eulerian vorticity flux. The result is shown in Fig. A2 for two choices of bottom friction $R$ and five choices of initial vorticity $\xi_{0}$. The initial vorticity flux can be up or down the slope, depending on $\xi_{0}$. But after the initial adjustment period (which depends inversely on $R$ ), the end result is always a positive vorticity flux towards deep water. The magnitude of the flux is linearly proportional to $R$, as can be deduced from Eq. (A6).

Data availability. Model data are available at https://doi.org/10.11582/2021.00095 (Børve and Nøst, 2021).

Author contributions. OAN and EB sat up the numerical model. EB conducted the numerical experiments and analyzed the data. All au- thors contributed to discussing and interpreting the results. EB and PEI wrote the initial draft, and all authors have contributed to editing the paper.

Competing interests. The contact author has declared that neither they nor their co-authors have any competing interests.

Disclaimer. Publisher's note: Copernicus Publications remains neutral with regard to jurisdictional claims in published maps and institutional affiliations.

Acknowledgements. We thank Trygve Halsne for providing the processed satellite images of Moskstraumen and Nordlandsflaget in Fig. 4. The satellite images come from the Copernicus Sentinel2 missions and are assessed and processed using data from the Norwegian National Ground Segment for Sentinel data. The observations shown in Fig. 7 are obtained from tide stations provided by the Norwegian Mapping Authority, Hydrographic service (https://api.sehavniva.no/tideapi_no.html, last access: 2 December 2021). Furthermore, we have used sea surface height fields from the TPXO 7.2 assimilated tidal model as boundary conditions for our model simulation and gratefully thank the authors for releasing the model data publicly. Bathymetry data were provided by the Norwegian Mapping Authority. We thank two anonymous reviewers and the editor for constructive feedback on the manuscript, and Dmitry Aleynik for commenting on the manuscript.

Financial support. This research has been supported by VISTA a basic research program in collaboration between the Norwegian Academy of Science and Letters and Equinor (project no. 6168).

Review statement. This paper was edited by Joanne Williams and reviewed by two anonymous referees.

\section{References}

Ådlandsvik, B. and Sundby, S.: Modelling the transport of cod larvae from the Lofoten area, ICES Mar. Sci. Symp., 198, 379-392, 1994.

Afanasyev, Y. D.: Formation of vortex dipoles, Phys. Fluids, 18, https://doi.org/10.1063/1.2182006, 2006.

Blauw, A. N., Beninca, E., Laane, R. W. P. M., Greenwood, N., and Huisman, J.: Dancing with the tides: fluctuations of coastal phytoplankton orchestrated by different oscillatory modes of the tidal cycle, PLoS One, 7, e49319, https://doi.org/10.1371/journal.pone.0049319, 2012.

Børve, E. and Nøst, O. A.: Lofoten 2D tidal simulation, Norstore [data set], https://doi.org/10.11582/2021.00095, 2021.

Bretherton, F. P. and Haidvogel, D. B.: Two-dimensional turbulence above topography, J. Fluid Mech., 78, 129-154, https://doi.org/10.1017/S002211207600236X, 1976. 
Bruggeman, J. and Bolding, K.: A general framework for aquatic biogeochemical models, Environ. Modell. Softw., 61, 249-265, https://doi.org/10.1016/j.envsoft.2014.04.002, 2014.

Chen, C., Beardsley, R., and Franks, P. J. S.: A 3-D prognostic numerical model study of the Georges Bank ecosystem. Part I: physical model, Deep-Sea Res. Pt. II, 48, 419-456, https://doi.org/10.1016/S0967-0645(00)00124-7, 2001.

Chen, C., Liu, H., and Beardsley, R. C.: An Unstructured Grid, Finite-Volume, Three-Dimensional, Primitive Equations Ocean Model: Application to Coastal Ocean and Estuaries, J. Atmos. Ocean. Tech., 20, 159-186, https://doi.org/10.1175/15200426(2003)020<0159:AUGFVT>2.0.CO;2, 2003.

Chen, C., Huang, H., Beardsley, R. C., Xu, Q., Limeburner, R., Cowles, G. W., Sun, Y., Qi, J., and Lin, H.: Tidal dynamics in the Gulf of Maine and New England Shelf: An application of FVCOM, J. Geophys. Res.-Oceans, 116, C12, https://doi.org/10.1029/2011JC007054, 2011.

Chen, C., Beardsley, R. C., Cowles, G., Qi, J., Lai, Z., Gao, G., Stuebe, D., Liu, H., Xu, Q., Xue, P., Ge, J., Hu, S., Ji, R., Tian, R., Huang, H., Wu, L., Lin, H., Sun, Y., and Zhao, L.: An Unstructured Grid, Finite-Volume Coastal Ocean Model: FVCOM User Manual, version 3.1.6, Marine Ecosystem Dynamics Modeling Laboratory, Sea Grant College Program Massachusetts Institute of Technology Cambridge, Massachusetts 0213, 4 edn., available at: http://fvcom.smast.umassd.edu/wp-content/uploads/2013/11/ MITSG_12-25.pdf (last access: 2 December 2021), 2013.

Cucco, A., Quattrocchi, G., Olita, A., Fazioli, L., Ribotti, A., Sinerchia, M., Tedesco, C., and Sorgente, R.: Hydrodynamic modelling of coastal seas: the role of tidal dynamics in the Messina Strait, Western Mediterranean Sea, Nat. Hazards Earth Syst. Sci., 16, 1553-1569, https://doi.org/10.5194/nhess-161553-2016, 2016.

Delandmeter, P., Lambrechts, J., Marmorino, G. O., Legat, V., Wolanski, E., Remacle, J.-F., Chen, W., and Deleersnijder, E.: Submesoscale tidal eddies in the wake of coral islands and reefs: satellite data and numerical modelling, Ocean Dynam., 67, 897913, https://doi.org/10.1007/s10236-017-1066-z, 2017.

Egbert, G. D. and Erofeeva, S. Y.: Efficient Inverse Modeling of Barotropic Ocean Tides, J. Atmos. Ocean. Tech., 19, 183-204, https://doi.org/10.1175/15200426(2002)019<0183:EIMOBO>2.0.CO;2, 2002.

Ellertsen, B., Solemdal, P., Strømme, T., Sundby, S., Tilseth, S., and Westgård, T.: Spawning period, transport and dispersal of eggs from the spawning area of Arcto-Norwegian cod (Gadus morhua L.), Rapp. P.-v. Reun. Cons. int. Explor. Mer, 178, 260267, 1981

Geyer, W. R. and Signell, R. P.: A reassessment of the role of tidal dispersion in estuaries and bays, Estuaries, 15, 97-108, https://doi.org/10.2307/1352684, 1992.

Geyer, W. R., Woodruff, J. D., and Traykovski, P.: Sediment transport and trapping in the Hudson River estuary, Estuaries, 24, 670-679, https://doi.org/10.2307/1352875, 2001.

Gjevik, B., Moe, H., and Ommundsen, A.: Sources of the Maelstrom, Nature, 388, 837-838, https://doi.org/10.1038/42159, 1997.

Halsne, T., Ferrighi, L., Saadatnejad, B., Budewitz, N., Dinessen, F., Breivik, L.-A., and Godøy, $\varnothing^{\prime}$.: The Norwegian National Ground Segment; Preservation, Distribution and Exploitation of Sentinel
Data, Data Sci. J., 18, 61, https://doi.org/10.5334/dsj-2019-061, 2019.

Hjermann, D. Ø., Melsom, A., Dingsør, G. E., Durant, J. M., Eikeset, A. M., Røed, L. P., Ottersen, G., Storvik, G., and Stenseth, N. C.: Fish and oil in the Lofoten-Barents Sea system: synoptic review of the effects of oil spill on fish populations, Marine Ecol Prog. Ser., 339, 238-299, https://doi.org/10.3354/meps339283, 2007.

Huthnance, J. M.: Tidal current asymmetries over the Norfolk Sandbanks, Estuar. Coast. Marine Sci., 1, 89-99, https://doi.org/10.1016/0302-3524(73)90061-3, 1973.

Isachsen, P. E., LaCasce, J. H., Mauritzen, C., and Häkkinen, S.: Wind-Driven Variability of the Large-Scale Recirculating Flow in the Nordic Seas and Arctic Ocean, J. Phys. Oceanogr., 33, 2534-2550, https://doi.org/10.1175/15200485(2003)033<2534:WVOTLR>2.0.CO;2, 2003.

Kashiwai, M.: Tidal Residual Circulation Produced by a Tidal Vortex. Part 1. Life-History of a Tidal Vortex, J. Oceanogr. Soc. Japan, 40, 279-294, https://doi.org/10.1007/BF02302521, 1984.

Kobayashi, M. H., Pereira, J. M., and Pereira, J. C.: A conservative finite-volume second-order-accurate projection method on hybrid unstructured grids, J. Comput. Phys., 150, 40-75, https://doi.org/10.1006/jcph.1998.6163, 1999.

Kundu, P. K., Cohen, I. M., Dowling, D. R., and Tryggvason, G.: Fluid Mechanics, Academic Press, Elsevier Inc, sixth edn., ISBN 978-0-12-405935-1, 2016.

LaCasce, J. H.: Statistics from Lagrangian observations, Prog. Oceanogr., 77, 1-29, https://doi.org/10.1016/j.pocean.2008.02.002, 2008.

Limeburner, R. and Beardsley, R. C.: Near-surface recirculation over Georges Bank, Deep-Sea Res. Pt. II, 43, 1547-1574, https://doi.org/10.1016/S0967-0645(96)00052-5, 1996.

Loder, J. W.: Topographic rectification of tidal currents on the sides of Georges Bank, J. Phys. Oceanogr., 10, 1399-1416, https://doi.org/10.1175/15200485(1980)010<1399:TROTCO>2.0.CO;2, 1980.

Lynge, B. K., Berntsen, J., and Gjevik, B.: Numerical studies of dispersion due to tidal flow through Moskstraumen, northern Norway, Ocean Dynam., 60, 907-920, https://doi.org/10.1007/s10236-010-0309-z, 2010.

Maas, L., Zimmerman, J. T. F., and Temme, N. M.: On the exact shape of the horizontal profile of a topographically rectified tidal flow, Geophys. Astrophys. Fluid Dynam., 38, 105-129, https://doi.org/10.1080/03091928708210107, 1987.

Maas, L. R. M. and Zimmerman, J. T. F.: Tide-topography interactions in a stratified shelf sea I. Basic equations for quasinonlinear internal tides, Geophys. Astrophys. Fluid Dynam., 45, 1-35, https://doi.org/10.1080/03091928908208891, 1989.

Moe, H., A., O., and B., G.: A high resolution tidal model for the area around The Lofoten Islands, northern Norway, Cont. Shelf Res., 22, 485-504, https://doi.org/10.1016/S02784343(01)00078-4, 2002.

Mork, M.: Experiments with theoretical models of the Norwegian Coastal Current, in: The Norwegian Coastal Current, edited by: Sætre, R. and Mork, M., 2, 518-530, University of Bergen, Bergen, 1981.

Norwegian Mapping Authority, Hydrographic Service: API for water level data, available at: https://api.sehavniva.no/tideapi_en. html (last access: 29 November 2021), CC BY 4.0, 2021. 
Nøst, O. A. and Børve, E.: Flow separation, dipole formation, and water exchange through tidal straits, Ocean Sci., 17, 1403-1420, https://doi.org/10.5194/os-17-1403-2021, 2021.

Ommundsen, A.: Models of cross shelf transport introduced by the Lofoten Maelstrom, Cont. Shelf Res., 22, 93-113, https://doi.org/10.1016/S0278-4343(01)00069-3, 2002.

Ommundsen, A. and Gjevik, B.: Scattering of tidal Kelvin waves along shelves which vary in their lengthwise direction, Preprint series, Mech. Appl. Math., available at: http://urn.nb.no/URN: NBN:no-28523 (last access: 29 November 2021), 2000.

Opdal, A. F., Vikebø, F. B., and Fiksen, Ø.: Relationships between spawning ground identity, latitude and early life thermal exposure in Northeast Arctic cod, J. Northwest Atlantic Fish. Sci., 41, 13-22, https://doi.org/10.2960/J.v41.m621, 2008.

Ou, H.-W.: A Model of Tidal Rectification by Potential Vorticity Mixing. Part I: Homogeneous Ocean, J. Phys. Oceanogr., 29, 821-827, https://doi.org/10.1175/15200485(1999)029<0821:AMOTRB>2.0.CO;2, 1999.

Ou, H.-W.: A Model of Tidal Rectification by Potential Vorticity Mixing. Part II: Frontal Regime, J. Phys. Oceanogr., 30, 564-571, https://doi.org/10.1175/15200485(2000)030<0564:AMOTRB>2.0.CO;2, 2000.

Parker, B. B.: The relative importance of the various nonlinear mechanisms in a wide range of tidal interactions, in: Tidal Hydrodynamics, 13, 237-268, John Wiley and sons, inc., ISBN 9780-471-51498-5, 1991.

Pingree, R. D. and Maddock, L.: Rotary currents and residual circulation around banks and islands, Deep-Sea Res. Pt. I, 32, 1, https://doi.org/10.1016/0198-0149(85)90037-8, 1985.

Polton, J. A.: Tidally induced mean flow over bathymetric features: a contemporary challenge for high resolution wide-area models, Geophys. Astrophys. Fluid Dynam., 109, 207-215, https://doi.org/10.1080/03091929.2014.952726, 2015.

Richardson, K., Visser, A., and Pedersen, F. B.: Subsurface phytoplankton blooms fuel pelagic production in the North Sea, J. Plankton Res., 22, 1663-1671, https://doi.org/10.1093/plankt/22.9.1663, 2000.

Robinson, I. S.: Tidal vorticity and residual circulation, DeepSea Res. Pt. I, 28, 195-212, https://doi.org/10.1016/01980149(81)90062-5, 1981.

Signell, R. P. and Butman, B.: Modeling tidal exchange and dispersion in Boston Harbor, J. Geophys. Res.-Oceans, 97, 1559115606, https://doi.org/10.1029/92JC01429, 1992.

Signell, R. P. and Geyer, R.: Transient eddy formation around headlands, J. Geophys. Res., 96, 2561-2575, https://doi.org/10.1029/90JC02029, 1991.
Smagorinsky, J.: General circulation experiments with the primitive equations: I. The basic experiment, Mon. Weather Rev., 91, 99-164, https://doi.org/10.1175/15200493(1963)091<0099:GCEWTP>2.3.CO;2, 1963.

Stommel, H. and Farmer, H. G.: On the nature of eustarine circulation. Part I (Chapters 3 and 4), techreport 52-88, Woods Hole Oceanographic Institution, MA, 1952.

Sundby, S. and Bratland, P.: Spatial distribution and production of eggs from North-East Arctic cod at the coast of northern Norway 1983-1985, Report series Fisken og Havet., Institute of Marine Research, Norway, 1, 1987.

Vikebø, F., Jørgensen, C., Kristiansen, T., and Fiksen, Ø.: Drift, growth, and survival of larval Northeast Arctic cod with simple rules of behaviour, Marine Ecol. Prog. Ser., 347, 207-219, https://doi.org/10.3354/meps06979, 2007.

Wells, M. G. and van Heijst, G.-J. F.: A model of tidal flushing of an estuary by dipole formation, Dynam. Atmos. Oceans, 37, 223 244, https://doi.org/10.1016/j.dynatmoce.2003.08.002, 2003.

Whilden, K. A., Socolofsky, S. A., Chang, K.-A., and Irish, J. L.: Using surface drifter observations to measure tidal vortices and relative diffusion at Aransas Pass, Texas, Environ. Fluid Mech., 14, 1147-1172, https://doi.org/10.1007/s10652014-9361-4, 2014.

White, M., Mohn, C., de Stigter, H., and Mottram, G.: Deepwater coral development as a function of hydrodynamics and surface productivity around the submarine banks of the Rockall Trough, NE Atlantic, Erlangen Earth Conference Series, Springer, https://doi.org/10.1007/3-540-27673-4_25, 2005.

White, M., Bashmachnikov, I., Arístegui, J., and Martins, A.: Physical processes and seamount productivity, Seamounts: ecology, fisheries and conservation, in: Seamounts: Ecology, Fisheries and Conservation, Blackwell publishing, chapter 4, 65-84, 2007.

Wright, D. G. and Loder, J. W.: A depth-dependent study of the topographic rectification of tidal currents, Geophys. Astrophys. Fluid Dynam., 31, 169-220, https://doi.org/10.1080/03091928508219269, 1985.

Zimmerman, J. T. F.: Topographic generation of residual circualtion by oscialltory (tidal) currents, Geophys. Astrophys. Fluid Dynam., 11, 35-47, https://doi.org/10.1080/03091927808242650, 1978.

Zimmerman, J. T. F.: Dynamics, diffusion and geomorphological significance of tidal residual eddies, Nature, 290, 549-555, https://doi.org/10.1038/290549a0, 1981. 